Article

\title{
Hierarchical Optimization Decision-Making Method to Comply with China's Fuel Consumption and New Energy Vehicle Credit Regulations
}

\author{
Kangda Chen ${ }^{1,2}$, Fuquan Zhao ${ }^{1,2}$, Han Hao ${ }^{1,2,3} \mathbb{D}$, Zongwei Liu ${ }^{1,2, *}$ and Xinglong Liu ${ }^{1,2} \mathbb{D}$ \\ 1 State Key Laboratory of Automotive Safety and Energy, Tsinghua University, Beijing 100084, China; \\ ckd16@mails.tsinghua.edu.cn (K.C.); zhaofuquan@tsinghua.edu.cn (F.Z.); hao@tsinghua.edu.cn (H.H.); \\ 1x119@mails.tsinghua.edu.cn (X.L.) \\ 2 Tsinghua Automotive Strategy Research Institute, Tsinghua University, Beijing 100084, China \\ 3 China Automotive Energy Research Center, Tsinghua University, Beijing 100084, China \\ * Correspondence: liuzongwei@tsinghua.edu.cn; Tel./Fax: +86-10-6279-7400
}

Citation: Chen, K.; Zhao, F.; Hao, H.; Liu, Z.; Liu, X. Hierarchical Optimization Decision-Making Method to Comply with China's Fuel Consumption and New Energy Vehicle Credit Regulations. Sustainability 2021, 13, 7842. https:// doi.org/10.3390/su13147842

Academic Editor: Rasoul Asaee

Received: 9 May 2021

Accepted: 7 July 2021

Published: 13 July 2021

Publisher's Note: MDPI stays neutral with regard to jurisdictional claims in published maps and institutional affiliations.

Copyright: (c) 2021 by the authors. Licensee MDPI, Basel, Switzerland. This article is an open access article distributed under the terms and conditions of the Creative Commons Attribution (CC BY) license (https:// creativecommons.org/licenses/by/ $4.0 /)$.

\begin{abstract}
The national targets of reaching carbon peak in 2030 and carbon neutrality in 2060 propose higher requirements for energy conservation and emission reduction of China's automobile industry. As an important measure for the government, the fuel consumption and new energy vehicle (NEV) credit policy system has a significant impact on the Chinese and even the global vehicle market. Considering the lack of a systematic evaluation model for China's fuel consumption and NEV credit regulations, this study establishes a hierarchical optimization decision-making model based on technology frontier curves and a multi-dimension database containing extensive data of technologies, products, and enterprises in the Chinese market to simulate and evaluate the technology compliance and policy impact under multiple regulations. The results show that, from the perspective of the technology frontier curve, gasoline technologies still have great cost-effectiveness advantages when the fuel-saving requirement is less than $46 \%$, and the space for plug-in hybrid electric vehicles (PHEVs) and range-extended electric vehicles (REVs) is gradually shrinking due to the cost reduction of battery electric vehicles (BEVs). BEV400 will be better than PHEV70 and REV100 when the fuelsaving requirement is higher than $79 \%$. Diesel vehicles are always not competitive in the passenger car market. In terms of the compliance of corporate average fuel consumption (CAFC) regulation, the start-stop technology will be gradually phased out and mild hybrid electric vehicles will be rapidly introduced due to their high cost-effectiveness in 2025. With the tightening of regulations, the penetration rate of BEVs and PHEVs will be $23.7 \%$ and $6.7 \%$, respectively, and mild hybrid electric vehicles will be gradually replaced by strong hybrid electric vehicles in 2030. By 2035, the penetration rate of BEVs and PHEVs will be $43.6 \%$ and $6 \%$ further. For the CAFC and NEV credit regulation (widely known as the dual credit regulation), the single-vehicle credit poses a greater impact on the penetration of NEVs than corporate credit percentage limitation and is the key factor that should be focused on. The NEV credit limitation in the dual credit regulation could push 'poor performance' automakers to produce the required number of NEVs and meet the bottom line. However, in the long term, when compared to the CAFC regulation, the dual credit regulation is more lenient, due to NEVs being able to get double benefits both on NEV credit and CAFC credit, and NEV credit can also unidirectionally compensate CAFC credit under the dual-credit policy context. With the increased penetration and cost reduction of NEVs, the 'averaging' effect of dual credit regulation will inhibit the development of energy-saving and new energy vehicles. Therefore, eliminating the connection between NEV credit and CAFC credit or only leaving the CAFC and the fuel consumption limit regulations in the future will be better for the long-term development of the energy-saving and new energy vehicle industry.
\end{abstract}

Keywords: fuel consumption; new energy vehicles; dual credit regulation; technology decisionmaking; passenger car 


\section{Introduction}

China's vehicle market has seen explosive growth over the past two decades, but at the same time, the industry is facing serious energy and environmental challenges. In 2020, China's automobile sales reached 25.31 million despite the impact of COVID-19, exceeding 20 million for eight consecutive years, ranking first in the world [1]. The number of vehicle ownership has reached 281 million [2] and is expected to reach 600 million by 2050 [3]. However, China's dependence on foreign crude oil has been increasing year by year, rising from $70.8 \%$ in 2019 to $73 \%$ in 2020 [4,5]. On top of that, China has been becoming the world's largest carbon dioxide emitter since 2006, accounting for about $27.6 \%$ of global carbon dioxide emissions due to the explosion of the automobile market [6], 9\% of which come from the transportation sector. On-road transportation is the key to energy conservation and emission reduction since it accounts for $80 \%$ of the industry's total carbon emissions [7]. It is projected that China's passenger vehicles will consume 520 million tons of equivalent oil and produce 2.15 billion tons of carbon dioxide emissions by 2050 without strengthening measures of policies [8].

At the 75th General Assembly of the United Nations in 2020, China committed that national carbon dioxide emissions will peak by 2030 and achieve carbon neutrality by 2060 [9]. The targets of carbon peak and carbon neutrality have raised a high demand for the low-carbon development of various industries. As an important field for China to achieve carbon neutrality by 2060, the automobile industry has an important impact on the energy conservation and emission reduction. According to Energy-saving and New Energy Vehicle (NEV) Technology Roadmap 2.0, China's automobile industry will strive to reach an emission peak around 2028, and to reduce the carbon emissions by $20 \%$ from the peak by 2035, to contribute to the realization of the national energy-saving and emission reduction and the overall goal of carbon neutrality [10].

To decrease the fuel consumption of the automobile industry and promote the development of NEVs, China has issued and implemented a series of policies about energy-saving and new energy vehicles since 2005, one of which is fuel consumption and the NEV credit policy system, mainly composed of corporate average fuel consumption (CAFC) and NEV credit regulation, supplemented by passenger car fuel consumption limit regulation. As the first mandatory energy conservation standard in China, the fuel consumption limit has been implemented in five phases since its introduction in 2005 [11-13], imposing a threshold constraint on single-vehicle fuel consumption. A vehicle model can be approved to market only when its fuel consumption is lower than the limit, or the models shall be forced to stop production or make modifications. CAFC policy further limits the average fuel consumption of enterprises based on single-vehicle limit standards and sets the single-vehicle target. Enterprises can accordingly plan model products and output under the overall CAFC compliance limit. The current CAFC policy was introduced in 2011 and has been formally implemented since the third stage in $2012[14,15]$. China officially implemented fuel consumption limits for passenger cars and fuel consumption evaluation methods and targets for passenger cars (Phase IV) in 2016, and the Phase V standard will be launched in 2021 [16,17], as shown in Figure 1. The implementation of fuel consumption limits and CAFC regulation has played a vital role in promoting the development and application of advanced energy-saving technology in China and continuously reducing the fuel consumption of passenger vehicles. 


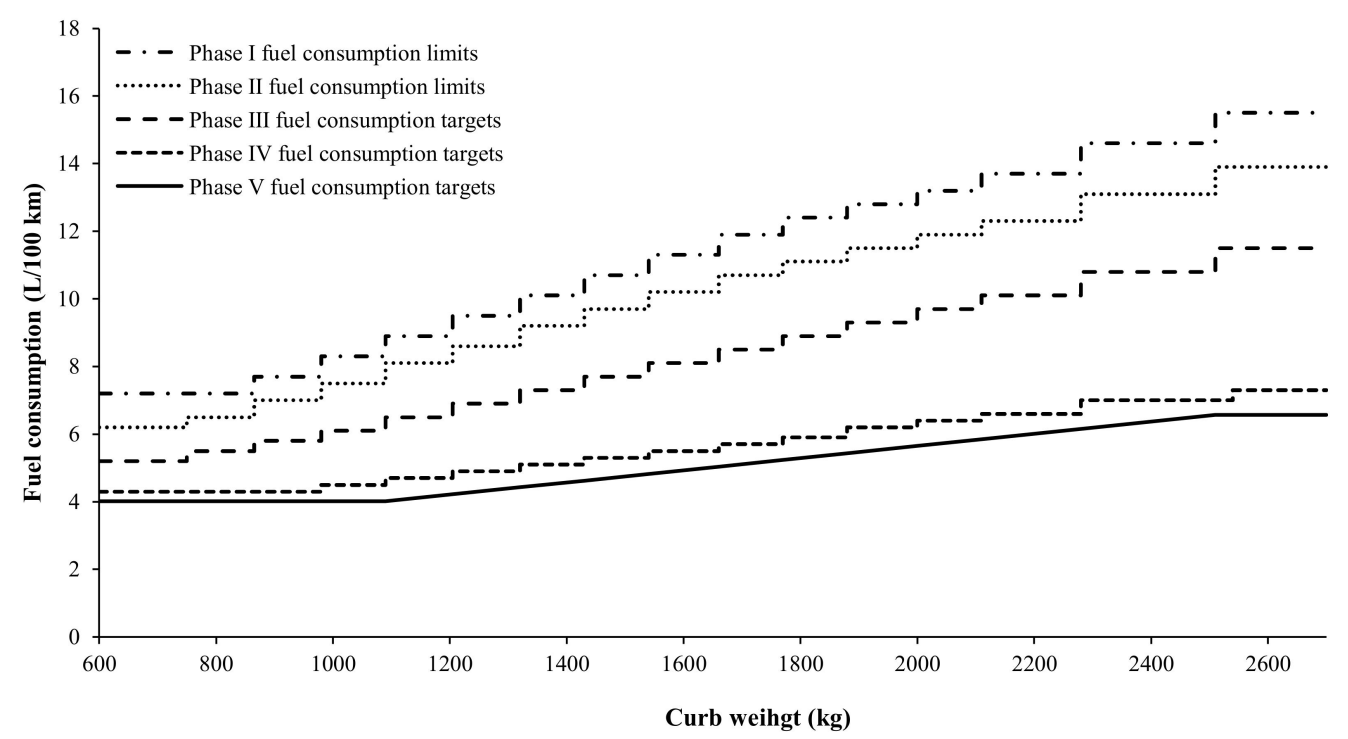

Figure 1. The target and limit values of China's Phase I-V fuel consumption regulations.

At the same time, to sustainably promote the development of NEVs, the dual credit regulation was officially implemented in April 2018 [18]. CAFC credits and NEV credits are coordinated and parallelly managed, as shown in Figure 2, to take the lead in establishing the long-term management mechanism of energy-saving and NEVs worldwide. The policy is one of the important symbols of the transition from policy-led to market-led development of NEVs in China. At the same time, due to the scale of the Chinese automobile market, the policy is expected to have a significant impact on the global NEV industry. The dual credit policy clearly defines the methods of calculation, transition, and transaction of the two types of credits. According to the policy, the mandatory proportion requirement is set for enterprise NEV credits, and NEV credits can one-way substitute the CAFC credits, to promote the development of NEVs. According to the influence of the previous policy and the market operation, the state made the first round of modifications to the calculation method of NEVs' credits and the dual credit policy and officially began to implement the new version of the policy in 2021 [19].

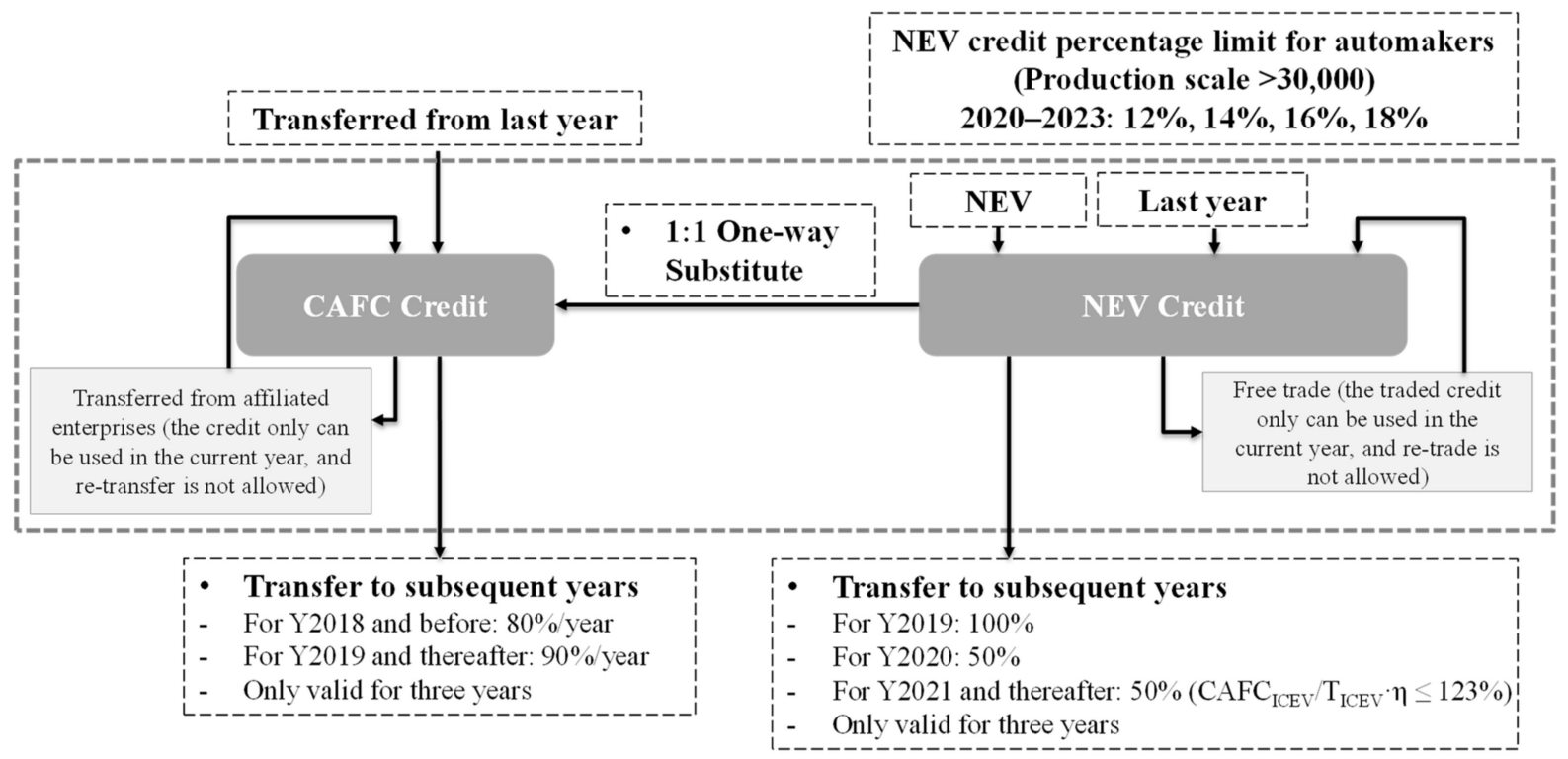

Figure 2. The framework of the dual credit regulation for passenger car enterprises. 
In general, China's fuel consumption regulation system has experienced transitions from the single fuel consumption limit to the dual management of fuel consumption limit regulation and the CAFC regulation, and then to the dual credit regulation. After more than ten years' development of regulation, China has initially formed a complete fuel consumption policy system, and the new dual credit regulation also provides a guarantee for the sustainable development of energy-saving and new energy vehicles. However, on the other hand, there are still many problems to be solved in the implementation, evaluation, and optimization of policies, as well as in the selection of technology pathways for industrial enterprises to comply with the standards.

There have been extensive studies on fuel consumption and fuel economy policies in the world and these studies can be roughly divided into three categories. The first one is a national level of a comprehensive evaluation model of fuel economy policies. It is a comprehensive evaluation of the technology effectiveness, cost, technology pathway selection, energy, and environmental benefits, social benefits, etc., providing simulations and all kinds of quantitative results to support policymakers. It is more systematic, comprehensive, and cutting-edge than general academic research. Among these, the research conducted by the United States and the European Union is the most authoritative and leading. The official regulatory evaluation models used by policymakers mainly include the OMEGA model of the US EPA, the VOLPE model of NHTSA, and the DIONE model of the European Union. EPA evaluates the energy-saving effect of the technology combination through the lumped parameter model (LPM), sorts the advanced technology combination according to the cost-effectiveness, defines the technology application sequence in advance, and then applies the technology combination to the predefined fleets in turn based on the OMEGA model. Through the measurement of different regulatory scenarios, the EPA evaluates the technology penetration and regulatory impact under different regulatory scenarios [20]. NHTSA classifies advanced energy-saving technologies into four categories and conducts a detailed evaluation of the effectiveness and cost of each category and subdivision technology. The Volpe model adopts the method of the technology decision tree, which sets 13 technology routes in advance, evaluates the order of technology application, and then introduces each technology route from top to bottom according to the technology decision tree, and makes traversal decisions for each technology. Based on the Volpe model, NHTSA conducted a comprehensive assessment of the impact of various technologies on traffic accidents, social costs, and social benefits, such as technological penetration, enterprise fuel economy improvement, technological cost input, and policy [21]. The DIONE model adopted by the EU is similar to the OMEGA and Volpe models in terms of regulatory evaluation. DIONE first uses the basic technology cost and emission reduction potential data, applies the idea of ant colony optimization to get the technology cost curve for different vehicle types and powertrains to achieve $\mathrm{CO}_{2}$ emission reduction, and then all kinds of cost curves are introduced into the cross-optimization model to carry out optimization calculation for each enterprise. The total cost of ownership and consumer payback cycle were calculated based on manufacturing cost, energy-saving cost, depreciation, and usage cost. At the same time, DIONE can carry out optimization calculations in the whole social transportation field (passenger transport and freight transport) in combination with the PRIMES-TREMOVE traffic model, and finally evaluate and calculate life cycle emissions and social benefits based on the calculation results of technology pathways [22,23].

The second category focuses on the research on the selection of technology pathways to comply with policies, which mainly adopts three decision-making methods in the world: combinatorial optimization, scenario analysis based on econometrics, and game theory. Mavirs and Kirby from the Georgia Institute of Technology proposed a comprehensive technology definition, evaluation, and selection method (TIES). The 8-step TIES method can effectively balance the conflicting goals and provide the optimal technology combination scheme for decision-makers by using a genetic algorithm [24]. Subsequently, Roth et al. proposed an adaptive technology selection method, in which genetic algorithms were used to effectively search the combination space of technologies, to obtain the best com- 
prehensive application results among conflicting goals $[25,26]$. Montalbo et al. aimed to help enterprises to decide the lightweight technology selection strategy for each type of vehicle and optimize the net present value of cash flows within the target period while meeting the corporate average fuel economy (CAFE) policy [27]. Maddulapalli et al. from General Motors proposed a method for optimal selection of vehicle product portfolio. This approach maximizes marginal gains in changing fuel prices while meeting CAFE policy and defines the problem as mixed integer non-linear programming [28]. Fellini et al. proposed a quantitative approach to platform selection and product family design. The goal of design is choosing a product platform, based on which the derived design cost is minimal. The relaxation method is used to solve the combinatorial optimization problem, and the computational intensity is greatly reduced [29]. Liu et al. adopted the nested multinomial Logit consumer demand model, took maximizing social surplus as the objective function, and simulated the regulatory compliance decision-making process of automobile manufacturers from 2011 to 2020 using the dynamic optimization method. The results showed that the contribution of technology application to regulatory compliance would be greater than the contribution of price adjustment strategy [30]. Taghavi et al. established the optimal product portfolio model under CAFE policy and the product combination is carried out considering the recognition and acceptance degree of consumers [31]. Wang et al. established a technology decision-making model to comply with CAFC regulations from the perspective of combinatorial optimization and designed a heuristic algorithm to solve the problem $[32,33]$.

In terms of the scenario analysis, Heywood and Cheah of MIT Sloan Automotive Lab analyzed the regulatory compliance situation under different sales combinations and different vehicle characteristics in the next 20 years. Based on the results, the feasibility of compliance with CAFE policy after 2016 was discussed, and the current situation of vehicle production planning and the challenges of introducing new automotive technologies in the market were considered [34]. Ricardo used the vehicle fuel economy simulation system to simulate the different levels of car policy standard situation and the corresponding technology combination to address the car companies in the face of the same country of different laws and policies [35]. Axmann et al. from Volkswagen proposed a decision structure for analyzing product portfolio strategies. The structure can be used to analyze when to apply which powertrain in which vehicle class and conduct a comprehensive analysis of the simulation environment [36]. In the field of game theory, Michalek et al. considered the vehicle performance, cost, and consumer demand, and set the profit maximization as the goal, using the game theory and the theory of market equilibrium to simulate and predict different manufacturers' product design and pricing strategy [37]. Shiau further applied Nash conditions to find the method of market equilibrium, obtained better solution efficiency, improved the operation scale of the model [38], and further analyzed the product strategies of enterprises to comply with CAFE policy with different stringency degrees [39].

The third category of research mainly focuses on the evaluation and optimization of the regulatory mechanism. Whitefoot and Skerlos revealed that the US CAFE policy would result in a $2-32 \%$ increase in the average vehicle size, and a $5-15 \%$ increase in carbon dioxide emissions [40]. The researchers from GM tested the lightweight technology in different test conditions and verified the inhibitory effect of lightweight technology on curb weight [41]. Sallee and Slemrod studied the impact of the ladder feature of the US 'Gas Guzzler Tax' and calculated the resulting welfare loss [42]. Hao et al. concluded that China's step-based CAFC policy would cause enterprises to manipulate the curb weight of vehicles [43]. Plotkin discussed the impact of fuel economy and greenhouse gas emission policy, the speed of introduction, and the regulatory structure on vehicles [44]. According to Michalek's modeling analysis, with the increase of fuel tax, the improvement of fuel efficiency at unit regulatory cost decreases, while CAFE policy can achieve higher average fuel efficiency per unit cost [45]. Austin and Dinan's research showed that fuel tax can rapidly reduce people's driving mileage in the short term, and ultimately drive people to choose vehicles with better fuel economy [46]. Rubin studied the impact of the credits 
transaction system with different degrees of flexibility on the enterprise's compliance cost [47]. Given the more stringent CAFE policy in the United States from 2017 to 2025, the system of credit storage, borrowing, and transfer can also help auto manufacturers cushion the policy, avoid fines, and not increase too much cost to meet CAFE policy [48]. Fischer compared the impact of flexible compliance systems such as credit trading, feebate, rebate, and credit-transferring on national fuel economy targets [49]. ICCT simulated the fuel economy of the same vehicle under various driving cycles and compared the standard values of different countries in the same unit and test procedure [50]. And gasoline cars in the EU are slightly lighter and slightly smaller than the Chinese passenger cars, and the fuel consumption standards in 2015 and 2020 are 16-19\% stricter than the corresponding standards in China [51].

As an important method to promote NEVs, the NEV credit policy, which originated from California in 1990 [52], has gone through several rounds of revisions and is now passed by 11 states, covering about $30 \%$ of the US automotive market $[53,54]$. The biggest difference between fuel consumption and NEV dual credit policy between China and the US is that China's dual credit policy realizes parallel management, and NEV credits can unidirectionally substitute the negative CAFC credits [55,56]. Walther and Maxell et al. adopted the method of control variables and designed different compliance scenarios to detect the synergistic effect of ZEV, CAFE, and GHG policies. The results show that the simultaneous action of the two policies will encourage automakers to introduce advanced powertrain technology earlier $[57,58]$.

In terms of the modeling and evaluation studies on China's dual credit regulation, Liu et al. analyzed the relationship between CAFC, NEV credits, and carbon quotas policy, and predicted the development of the NEV market [59,60]. Zou et al. established a compliance model of dual credit policy with the minimum sales volume of NEVs as the target by fixing the credits price. The results showed that dual credit policy brought increased pressure on enterprises to meet the standards [61]. Wang et al. proposed the most cost-effective technical strategy to meet the requirements of the policy for four typical automobile manufacturers in the Chinese market [62]. Ou et al. simulated and compared different policy scenarios (CAFC-only, NEV-only, dual credit) from 2016 to 2020, and quantitatively analyzed the impact of dual credit policy on BEV and PHEV sales volume and corporate profits [63]. Taking profit maximization as the objective function, Li et al. analyzed the technical decision-making pathway of 12 Chinese automakers under the dual credit policy and NEV subsidy policy, and the results showed that the contribution of dual credit policy to NEV market penetration was twice that of the subsidy policy [64]. Chen et al. studied the impact of NEV credit regulation on the technology development of BEVs and the synergistic impacts of China's subsidy policy and new energy vehicle credit regulation $[65,66]$. He et al. combined the fleet model with the market penetration model to examine factors such as oil price, battery cost, charging infrastructure, and assessed the impact of the dual credit policy on greenhouse gas emissions and energy consumption in China by setting different scenarios. The research showed that the total GHG emissions of China's passenger fleet will reach the peak in 2032. Meanwhile, if more efficient internal combustion engine vehicles are adopted in the short term and more NEVs are adopted in the long term, the total greenhouse gas emissions can be significantly reduced [67].

However, a national-level technology decision-making and fuel consumption policy evaluation model has not yet been established in China. At the same time, few studies examine the synergistic impact of different regulations on the technology pathway, compliance cost, automaker's strategy, and the development of the whole fleet. While facing the growing market scale, the complex market environment, and the increasingly serious energy and environmental challenge, a comprehensive evaluation model is urgently needed to evaluate the rationality and comprehensive impact of regulations and improve the applicability of national policy. 
To fill these research gaps, this paper first establishes a comprehensive database containing technology cost and effectiveness, vehicle parameters, and market structures in China. After that, a hierarchical optimization decision-making model based on the technology frontier curve is established. It comprehensively considers the three dimensions of technology, policy, and market, and conducts systematic policy modeling evaluation for the whole industry. In the end, the policy simulation and compliance research for 2021-2035 under the multiple policies are realized, and a systematic evaluation is conducted on the technology pathway, compliance cost, policy design, energy consumption improvement, etc. This research includes technology decision method research, policy scenario simulation, technology trend prediction, and policy implication analysis. The paper is organized as follows. Section 2 describes the research framework, methodology, key assumptions, and data; Section 3 analyzes and discusses the results of the whole policy simulation and compliance research during 2021-2035 under the multi-policy scenario. Section 4 introduces the policy implications, proposes recommendations to the government and automakers, and summarizes the whole study.

\section{Methods and Data}

Technology pathways decision-making and policy modeling can be defined as a multilayer combinatorial optimization problem. The objective function is complying with the regulations with the lowest incremental technology cost, and the constraints are technology compatibility, technology limit, and policy requirements. Finally, the optimization and evaluation of the technology pathway, compliance cost, and social benefits of automakers and the whole industry could be conducted based on the model. To solve this problem, this study establishes a technology selection model based on hierarchical optimization, and the overall logical structure of the model is shown in Figure 3. Based on the idea of the nested model, the whole model is divided into three layers. The first layer is the technology compatibility matrix, containing complex characteristics of vehicles and technologies, such as technology cost, fuel reduction effect, vehicle segment, and so on. The second layer is the technology frontier curve that is obtained by Pareto optimization. The second layer generates a huge number of technology portfolios and selects the optimal groups. The third layer is the technology selection model, considering the features of baseline fleet, technology deployment, product structure of original equipment manufacturers (OEMs), and the whole market. By importing the technology frontier curve, the problem is further defined as a mixed integer non-linear program (MINLP) problem and the optimal technology pathway for each automaker could be obtained by compound BONMIN algorithm on the premise of meeting the regulations.

\subsection{Multi-Dimension Database}

For the Chinese market, this study established a complete database including a huge number of data related to technology, product, enterprises, and market. The establishment of the technology database, including data sources, acquisition methods, processing methods are described in detail in another related research [68].

The sources of technology data mainly include US National Research Committee (NRC), Ricardo, Joint Research Center (JRC), International Council on Clean Transportation (ICCT), China Automotive Technology \& Research Center (CATARC), and an enterprise survey. The database covers 4 categories (engine, transmission, vehicle and accessory, electric), 6 types of powertrains, and 64 technologies. In addition, as shown in Figure 4, the sources of market and product data mainly include the fuel consumption database of the Ministry of Industry and Information Technology (MIIT), CATARC, Auto Home, etc. The data were acquired, cleaned, and matched by Python. Finally, a complete database for the Chinese vehicle market was established. The database contains all 144 automakers, nearly 700 vehicle models (after screening) of the whole market in 2019, and all product parameters, such as curb weight, energy consumption, sales, and technology deployment. 


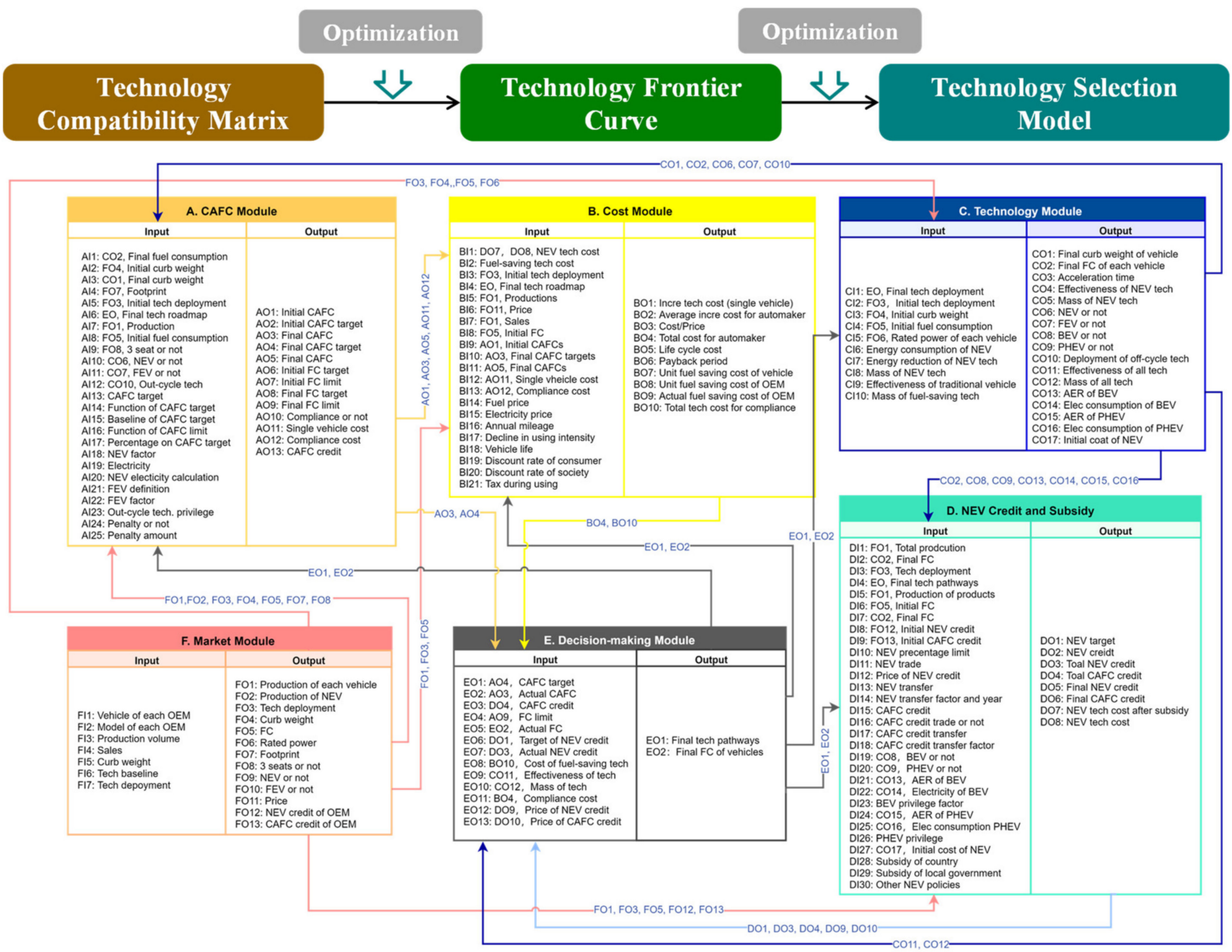

Figure 3. The framework and modules of the technology selection model.

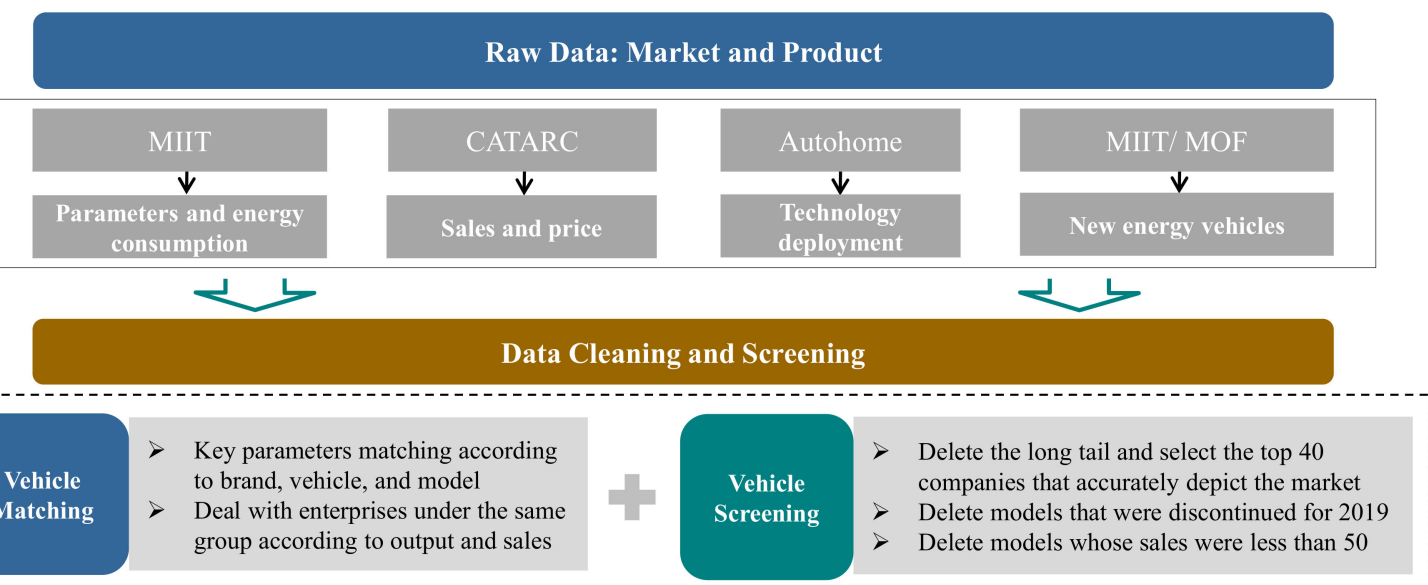

Companies Range: All 144 automakers in the Chinese market from 2015 to 2019 , including 119 domestic companies and 25 imported companies
Vehicles Range: Nearly 700 models (after screening) from 144 companies in the whole market, covering the latest models in 2019

Figure 4. Market and product database.
Parameters Range: Curb weight, energy consumption, sales, all technology deployment (including 64 technologies, for example engine, transmission, battery, etc.) 


\subsection{Optimization of Technology Frontier Curve}

In this part, we built a bottom-up model to optimize the underlying technologies and get the technology frontier curves. Four segments of vehicles (as shown in Table 1, including small, compact, midsize, and large) and six types of powertrains (gasoline, diesel, HEV, PHEV, REV, and BEV), 64 energy-saving and new energy technologies were considered. The specific levels and quantities are shown in Figure 5.

Table 1. Parameters of reference vehicle segments.

\begin{tabular}{|c|c|c|c|c|c|c|}
\hline $\begin{array}{l}\text { Segment } \\
\text { Parameter }\end{array}$ & Curb Weight (kg) & $\begin{array}{l}\text { Gasoline Vehicles } \\
\text { Wheelbase (m) }\end{array}$ & Footprint $\left(\mathrm{m}^{2}\right)$ & Curb Weight (kg) & $\begin{array}{l}\text { Diesel Vehicles } \\
\text { Wheelbase (m) }\end{array}$ & Footprint $\left(\mathrm{m}^{2}\right)$ \\
\hline Small & 1090 & 2.5 & 3.6 & 1240 & 2.5 & 3.7 \\
\hline Compact & 1380 & 2.7 & 4.1 & 1510 & 2.7 & 4.1 \\
\hline Midsize & 1520 & 2.8 & 4.3 & 1660 & 2.8 & 4.3 \\
\hline Large & 1850 & 3.0 & 4.6 & 1930 & 3.0 & 4.7 \\
\hline
\end{tabular}

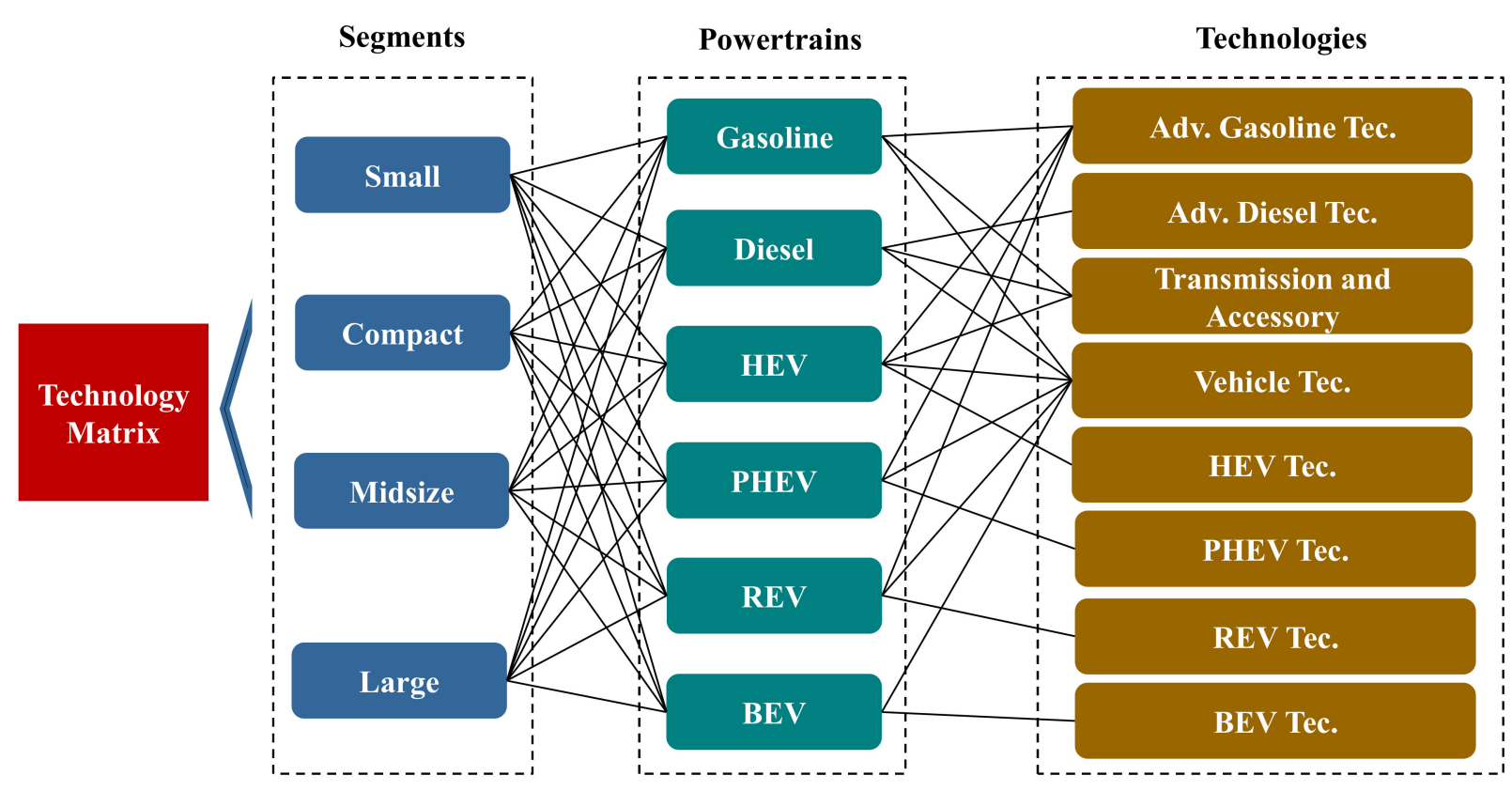

Figure 5. Hierarchies of the technology matrix.

According to a large number of technical reports, we evaluated the technical synergy and compatibility of 64 advanced energy-saving and new energy technologies and constructed the technology compatibility matrix as shown in Figure 3. There are five categories of technical compatibility constraints: (1) incompatibility of different powertrain technologies, that is, the technology applied to a specific powertrain cannot be applied to other powertrains, for example, gasoline engine direct injection technology cannot be applied to a diesel engine or BEV; (2) incompatibility of similar technologies, which means the same type of technology cannot be applied at the same time, for example, CVT and AMT cannot be applied in the same vehicle at the same time; (3) incompatibility of the same technology with different degrees, for example, $5 \%$ lightweight technology and $10 \%$ lightweight technology cannot be applied at the same time; (4) incompatibility of the application effect which can be offset or have strong coverage, that is, under the same energy-saving principle, those technologies will produce " $1+1<2$ " effect and will not be applied at the same time; and (5) technical constraints brought by accounting privilege under specific policies. For example, although BEVs consume energy, the fuel consumption is calculated as 0 in the present fuel consumption policies. Therefore, for BEVs, there is no need to adopt other energy-saving technologies to further improve energy efficiency under the CAFC regulation. 
Through the establishment of a technical compatibility matrix, all levels of internal technical constraints can be defined, and technologies in each level including the gasoline engine, diesel engine, gearbox and accessories, vehicle, etc. can be combined. We can further calculate the technical combination effect and cost at all levels and use the greedy algorithm to pre-filter and sort the technology portfolios. Through the comparisons of different technology portfolios, the combinations with inferior effects and costs were deleted, and the rest of the technology portfolios were ranked according to their technical effects. The procedure is shown in Figure 6.

\section{Technical preordering}

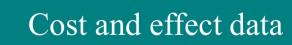

of 64 technologies in

different years

Technology portfolio screening

Arrange retained

technology

combinations
Cost-effectiveness and

ranking of technologies

Eliminate poor

performance

combination

\section{Define technical constraints}
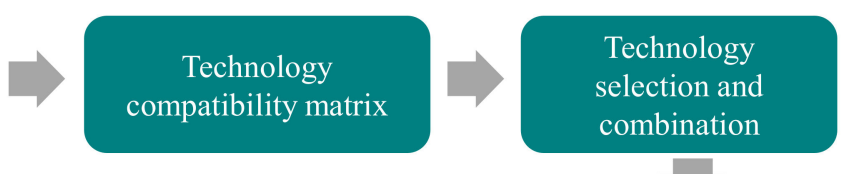

Technology combination

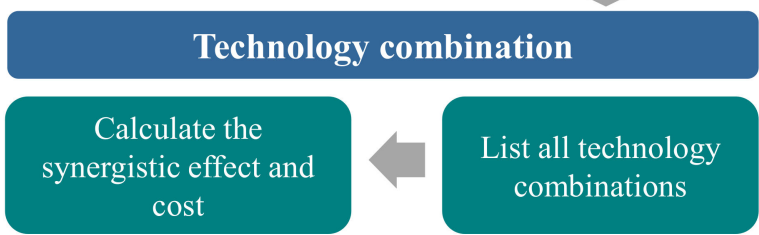

Figure 6. The processing flow of technology combination optimization.

Based on the optimization results of the technology portfolios, the technology combination between different categories was conducted for five types of powertrain vehicles, as shown in Figure 5. For example, for traditional gasoline vehicles, advanced gasoline technologies, transmission and accessory technologies, and vehicle technologies can be applied, and the final technology portfolio of traditional gasoline vehicles can be further optimized to 21,896 technology combinations. For HEVs, advanced gasoline technologies, transmission and accessory technologies, vehicle technologies, and HEV technologies (start-stop, micro hybrid, mild hybrid, strong hybrid) can be applied; the final technology portfolio of HEVs can be further optimized to 90,160 technology combinations. Finally, the technology combination cloud maps of all powertrains can be obtained by Matlab. Here, taking the midsize vehicles as an example, the combination cloud maps of different powertrains in 2025 are shown in Figure 7.

For all technology portfolios in the cloud maps of different powertrains, there are a series of Pareto optimal points. By comparing the points in the cloud maps, the Pareto optima have the following characteristics: under the same technology energy-saving effect, the technology cost of Pareto optima is less than any other points; while under the same technology cost, the energy-saving effect of Pareto optima is greater than any other points, as shown in Equations (1) and (2):

$$
f_{n}=f_{m} \text { and } c_{n}<c_{m}
$$

or

$$
c_{n}=c_{m} \text { and } f_{n}>f_{m}
$$

where $n$ and $m$ are the sequence number of the different portfolios, $f$ is the energy-saving effect of the technology portfolio, and $c$ is the cost of the technology portfolio. 


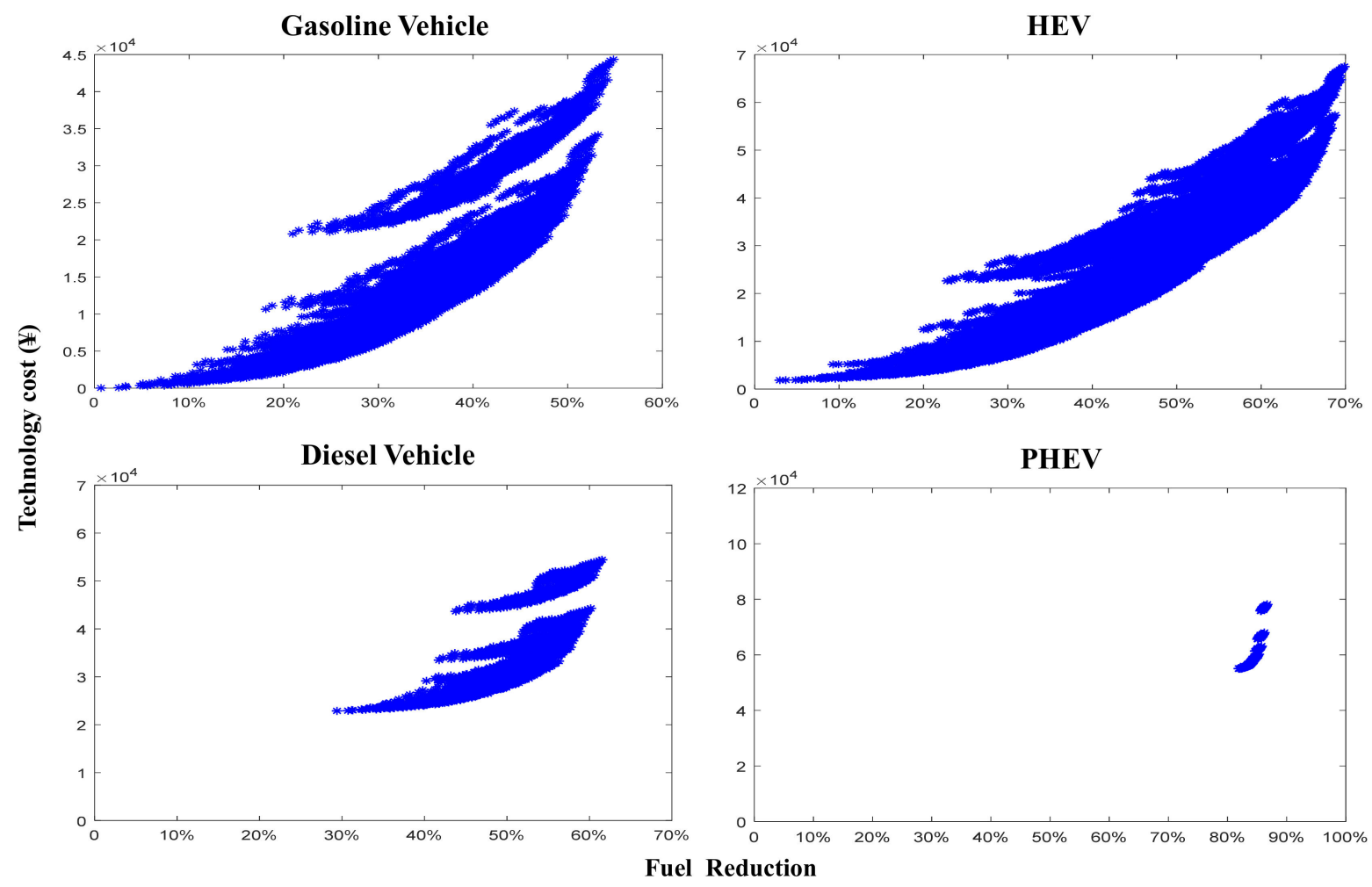

Figure 7. Technology portfolios of different powertrains.

To obtain Pareto optimal sets of different cloud maps, a sliding window algorithm was developed to further optimize the cloud maps. The algorithm logic diagram is shown in Figure 8. In the algorithm, the long sawtooth noise was eliminated by the double sliding windows to ensure the data quality of the Pareto optimal data set. The sliding window also had a performance trade-off: the wider the pane, the more likely it is to miss the optimal point; the narrower the pane, the more noise points and zigzags will occur. Therefore, the parameters should be adjusted according to the needs of different powertrain clouds to achieve optimal results. For a traditional gasoline car, the width of the transverse pane is set to 0.002 and the width of the longitudinal pane is set to 100.

By applying the optimization algorithm, the Pareto optimal point set and the corresponding optimal technology portfolios could be obtained. Based on the Pareto optimal point set, the spline interpolation algorithm was further used to fit the Pareto optimal point set, and the regression equation of the technology frontier curve was obtained. The spline interpolation method is widely used in the field of automotive dynamic trajectory optimization and has higher accuracy and strong ductility. The algorithm condition is:

(1) The function passes through known nodes;

(2) 0-order continuity at segment-connecting nodes;

(3) The first derivative at all nodes is continuous;

(4) The second derivative at all nodes is continuous.

Technology frontier curves of the different powertrains were obtained through multistep optimization. The same methods were applied to get the curves between technology effectiveness and technology mass. The technology frontier curves mainly cover 3 attributes: technology cost, effect, and mass, and three dimensions: time, vehicle type, and powertrain type. Finally, 160 technology frontier curves were obtained through technology combination optimization, covering four segments from small to large, six powertrains, and four different years. The technology frontier curve is vital for the selection of the technology pathway of the industry. It can help to get a more comprehensive analysis and achieve quantitative guidance from the perspective of technical characteristics. At the same 
time, as the hierarchical interface of the technology selection model, the technology frontier curve is the core to connect the technology layer and the enterprise layer.

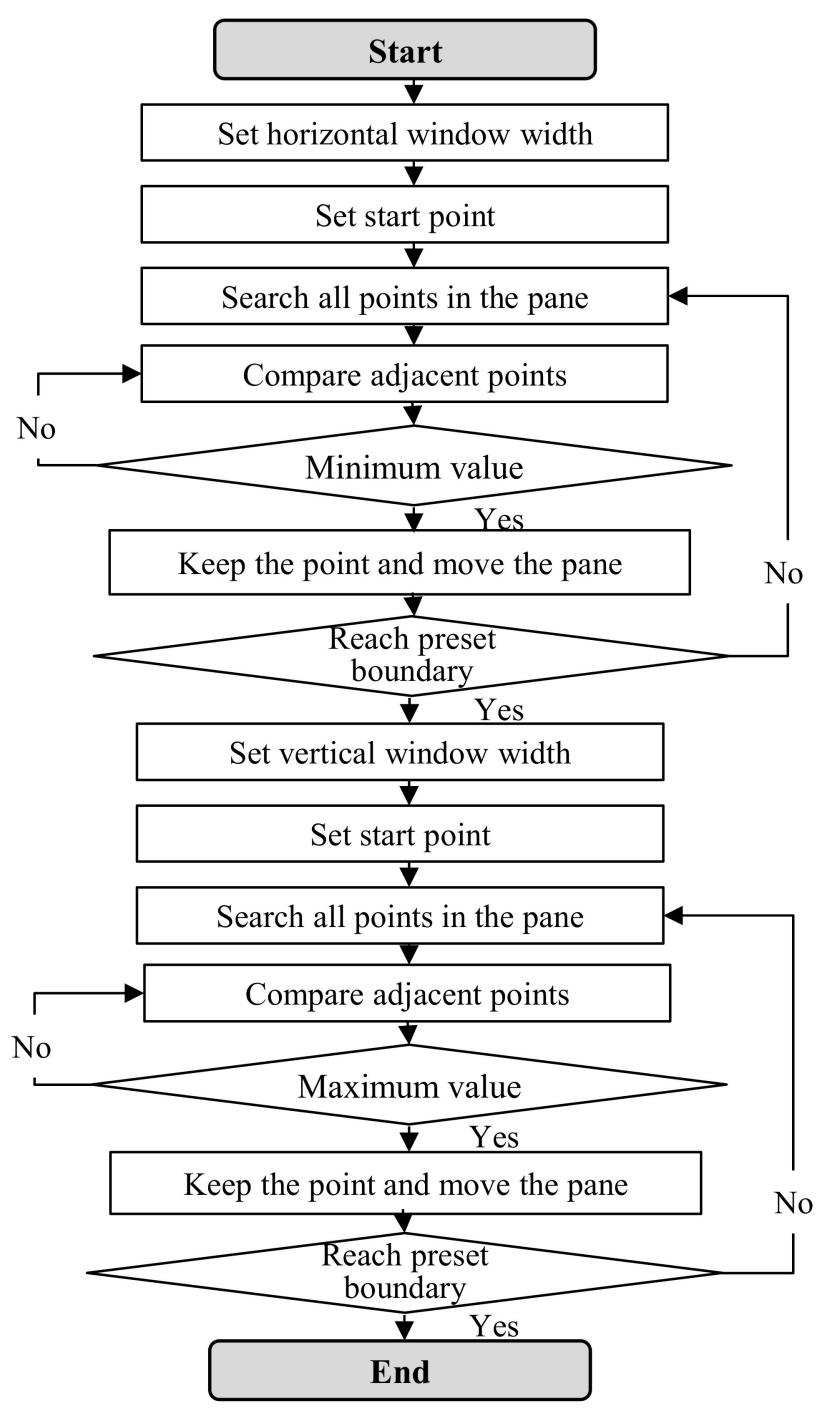

Figure 8. The logic diagram of the sliding window algorithm.

\subsection{Technology Selection Model for Automakers}

The decision-making steps of the technology selection model can be summed up as follows. First, for each vehicle of a certain automaker, the selection was made between technology frontier curves of different powertrains. Then, detailed technologies were selected along the frontier curve. Meanwhile, the fuel consumption limit and target of the vehicle were determined by the baseline fuel consumption and incremental technology deployment. After that, extensive calculations of iterative optimization about whether they meet the regulations and the corresponding compliance cost for the whole enterprise were conducted. Finally, the best technology pathway was optimized to comply with regulations at the lowest cost. The hierarchical optimization decision-making model based on the technology frontier curve can be defined as the mixed integer non-linear program (MINLP) problem. Through the introduction of the technology frontier curve, the number of variables can be greatly reduced, and the exponential explosion of the calculation amount of large-scale combinatorial optimization can be solved. At the same time, the technology frontier curve breaks through the solution limitation brought by the discrete data set. The mathematical model of technology selection model under CAFC and NEV 
credit regulations can be expressed as Equations (3)-(6), and the main parameters and definitions of the model are shown in Table 2.

$$
\begin{gathered}
\min \left(\sum_{y} \sum_{j=1}^{n} s_{j, y} \sum_{i=1}^{m}\left(x_{i, j, 0}-x_{i, j, y}\right) c_{i, y}+p_{N E V, y} R_{N E V, y}\right) \\
\left\{\begin{array}{c}
t_{j}=f_{\text {Target }, y}\left(m_{j}\right) \\
T_{C A F C}=\frac{\sum_{j} s_{j} \cdot t_{j}}{\sum_{j} s_{j}} \\
C A F C=\frac{\sum_{j}^{j} s_{j} \cdot f_{j}}{\sum_{j} s_{j} \cdot w_{j}} \\
Q_{C A F C}=\left(T_{C A F C} \cdot \alpha-C A F C\right) \cdot \sum_{j} s_{j} \\
f_{j} \leq l_{j}=f_{\text {Limit, } y}\left(m_{j}\right) \\
Q_{N E V}=\sum_{i=1}^{N_{N E V}} C_{i} \cdot s_{N E V, i}-\left(\sum_{i=1}^{N_{I C E V}} s_{I C E V, i}+\sum_{i=1}^{N_{L I C E V}} s_{L I C E V, i} \cdot \alpha_{i}\right) \times P_{y} \\
Q_{N E V} \geq 0 \\
Q_{C A F C}+Q_{N E V} \geq 0
\end{array}\right.
\end{gathered}
$$

Equation (3) is the objective function of the model, which means the automaker meets the policy with the minimum incremental cost. Equation (4) represents the parameters and calculations of CAFC regulation. Equation (5) represents the constraints of fuel consumption limit standard. Equation (6) represents the constraints of dual credit regulation. If there is no dual credit regulation, the constraint of CAFC-only will be:

$$
Q_{C A F C}>0
$$

Table 2. Main parameters and definitions of the model.

\begin{tabular}{cc}
\hline Parameters & Description \\
$i \in \mathbb{Q}=\{1,2, \ldots, m\}$ & Collection of fuel-efficient technologies available to OEMs \\
$j \in \mathbb{Z}=\{1,2, \ldots, n\}$ & Collection of OEMs' vehicle models \\
$y \in \mathbb{R}$ & Corresponding year \\
$f_{\text {Limit, }}\left(m_{j}\right)$ & Function of fuel consumption limit \\
$f_{T \operatorname{rag} e t, y}\left(m_{j}\right)$ & Function of fuel consumption target \\
$\mathbf{C}_{y}=\left[c_{1, y}, c_{2, y}, \ldots c_{m, y}\right]$ & Cost of energy-saving technology \\
$\mathbf{E}=\left[e_{1}, e_{2}, \ldots, e_{m}\right]$ & Energy-saving effectiveness of technology, $0 \leq e_{i} \leq 1$ \\
$\mathbf{F}_{y}=\left[f_{1, y}, f_{2, y}, \ldots f_{n, y}\right]$ & Fuel consumption after technology application \\
$\mathbf{L}_{y}=\left[l_{1, y}, l_{2, y}, \ldots l_{n, y}\right]$ & Fuel consumption limit after technology application \\
$\mathbf{M}_{y}=\left[m_{1, y}, m_{2, y}, \ldots m_{n, y}\right]$ & Mass of vehicles after technology application \\
$\mathbf{S}_{y}=\left[s_{1, y}, s_{2, y}, \ldots s_{n, y}\right]$ & Production volume of vehicles \\
$\mathbf{T}_{y}=\left[t_{1, y}, t_{2, y}, \ldots t_{n, y}\right]$ & Fuel consumption target after technology application \\
$\mathbf{W}_{y}=\left[w_{1, y}, w_{2, y}, \ldots, w_{n, y}\right]$ & Privilege factor of NEVs \\
$\mathbf{X}_{y}=\left[\mathbf{x}_{1, y}, \mathbf{x}_{2, y}, \ldots, \mathbf{x}_{n, y}\right]$ & Technology decision vector of model $\mathbf{j}$ \\
$Q_{C A F C}$ & Number of CAFC credit \\
$p_{N E V, y}$ & Unit price of NEV credit \\
$R_{y}$ & Number of credit lacked \\
$\mathbf{F}_{0}, \mathbf{L}_{0}, \mathbf{M}_{0}, \mathbf{S}_{0}, \mathbf{T}_{0}, \mathbf{W}_{0}, \mathbf{X}_{0}$ & Initial parameters and technology application \\
\hline
\end{tabular}

As described before, in order to reduce the size of the computation, this study selected the top 40 OEMs (considering the production volume) in the Chinese market to represent the fleet. Among the 40 OEMs, there are 35 domestic OEMs (including 19 joint ventures and 16 self-owned brands) and 5 foreign OEMs. The total production volume of the 40 selected OEMs in 2019 was 19.49 million, covering 93\% of the whole Chinese market. 
Among them, the coverage rate of domestic OEMs was 35/119, and the production volume coverage rate was $94.1 \%$. The coverage rate of foreign OEMs was $5 / 25$, and the production volume coverage rate was $72.3 \%$. At the same time, in the screening of vehicle models, for energy-saving vehicles, models with a sales volume of less than 50 were deleted. For NEVs, considering the privilege of NEVs under the current policies, all NEVs were retained.

\section{Results and Discussion}

To comply with China's CAFC and NEV credit regulations, this study established a comprehensive technology selection and regulation evaluation model assessing the impact of multi-regulation synergy and multi-factor coupling, and finally realized the optimization evaluation of energy-saving and new energy technology selection from the perspective of powertrain, vehicle, enterprise, and fleet. The synergistic effects of multiple regulations were compared and evaluated from different dimensions. The results are presented in three aspects as follows.

\subsection{Technology Frontier Curve}

The technology frontier curve could guide the technology roadmap of the industry from the perspective of technical characteristics, by objectively displaying the advantages and disadvantages of different powertrains and the optimal application range. As the application programming interface (API) of the technology selection model, the technology frontier curve also plays an important role in connecting the technology layer and the enterprise layer in the hierarchical optimization model. A total of 160 technology frontier curves were obtained in the study through technology combination optimization, covering four segments (small, compact, midsize, and large), six powertrains (gasoline, diesel, HEV, PHEV, REV, and BEV), and four different years (2020, 2025, 2030, and 2035). Whereas the core component of new energy vehicles, battery technology has a profound impact on the development of the whole new energy vehicle market. However, projections for the energy density and cost of battery technology are inconsistent in different countries because of different situations and resources. In this paper, the energy density and cost of battery system are set according to the predictions of CATARC and the Chinese technology roadmap $1.0[69,70]$.

As an example, Figure 9 shows the technology frontier curves of midsize vehicles from 2025-2035, where the fuel-saving rate represents the reduction percentage in fuel consumption of the final vehicle (after the deployment of advanced technologies) compared to the baseline vehicle.

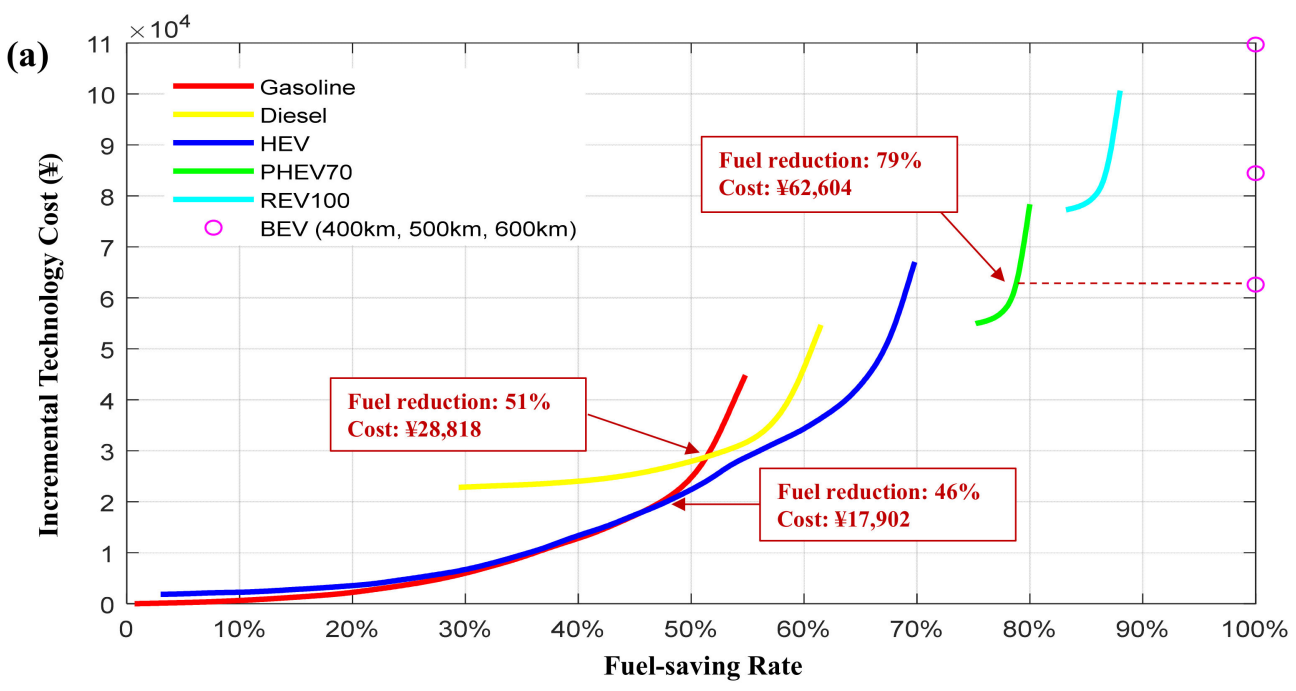

Figure 9. Cont. 

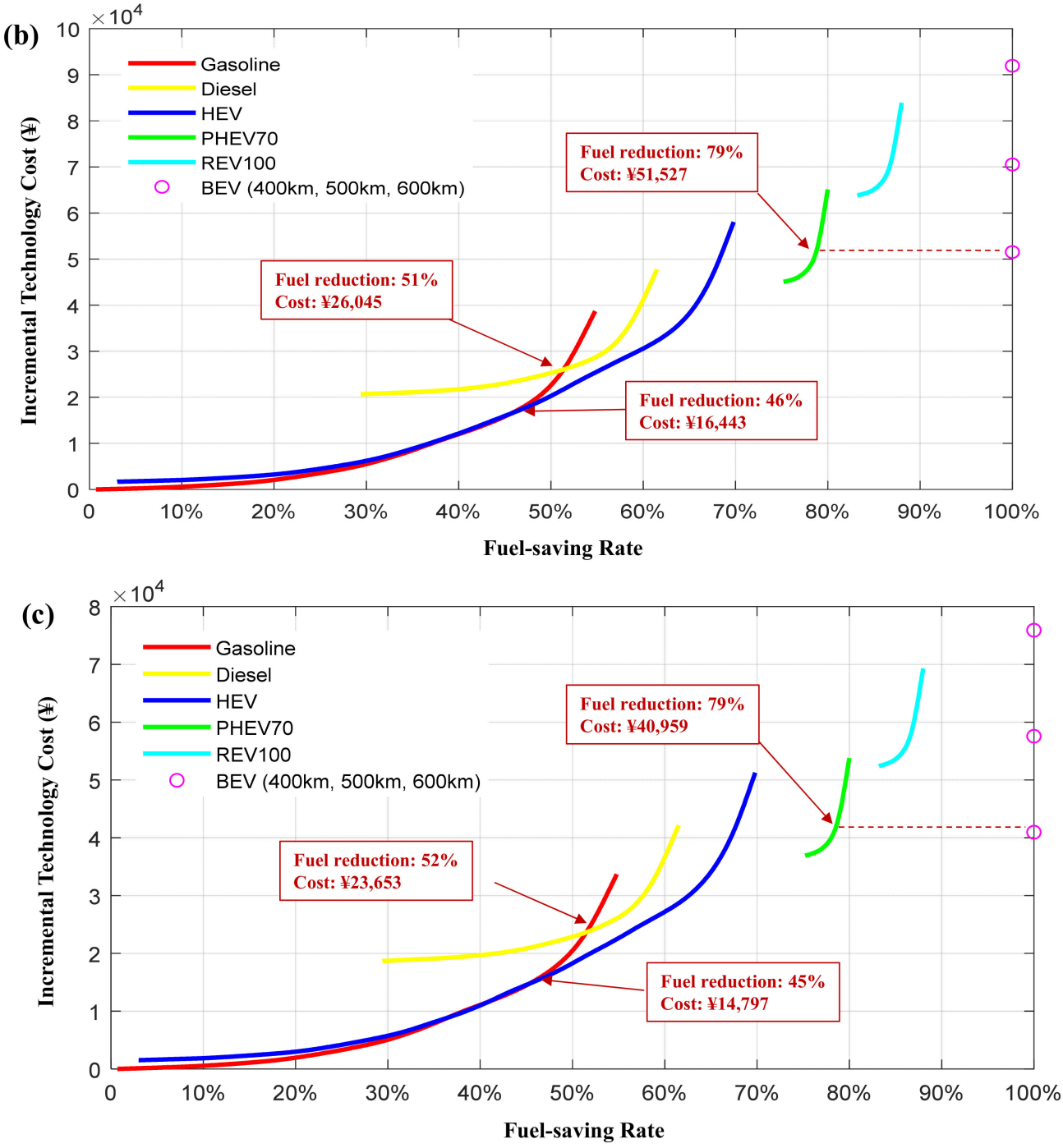

Figure 9. Technology frontier curves of midsize vehicles from 2025-2035.

For midsize vehicles, when the fuel-saving requirement is less than $46 \%$ or the incremental technology cost is less than $¥ 17,900$ in 2025 , the gasoline vehicle is the optimal technology pathway, whose cost is lower than that of HEV. When the fuel-saving requirement is higher than $51 \%$, the diesel vehicle is better than the gasoline vehicle, but neither has the advantage compared to the HEV in this range. When the fuel-saving requirement is higher than $79 \%$ or the total powertrain cost is over $¥ 62,604$, BEV400 (BEV with an average electric range of $400 \mathrm{~km}$ ) is superior to the PHEV70 (PHEV with an average electric range of $70 \mathrm{~km}$ ) and REV100 (REV with an average electric range of $100 \mathrm{~km}$ ). In 2030, when the fuel-saving requirement is less than $46 \%$ or the incremental technology cost is less than $¥ 16,440$, the gasoline vehicle is the optimal technology pathway. When the fuel-saving requirement is higher than $51 \%$, the HEV is the optimal technology pathway. Moreover, if the fuel-saving requirement is higher than $79 \%$ or the incremental technology cost is more than $¥ 51,527$, BEV400 is better than PHEV70 and REV100. In 2035, when the fuel-saving requirement is less than $45 \%$ or the technology budget is less than $¥ 14,797$, the gasoline vehicle is the optimal technology pathway and when the fuel-saving effect of the whole vehicle is above $45 \%$, HEV is the optimal technology pathway. When the fuel-saving requirement is higher than $79 \%$ or the total powertrain cost is over $¥ 40,959, \mathrm{BEV} 400$ is better than PHEV70 and REV100. Generally, with the cost reduction of BEVs, the application space of PHEVs and REVs is gradually shrinking. In addition, diesel engines never have the advantage of cost-effectiveness in the passenger car market. 


\subsection{Technology Pathways to Comply with the CAFC Regulation}

Based on the comprehensive database and the technology selection model established in Section 2.3, technology pathways to comply with the CAFC regulation of the whole industry were studied. As described before, under the CAFC regulation, every automaker will make their technology strategy and adjust their product matrix to comply with the regulation. The technology selection model designed in this study simulated the decision-making and technology selection process of automakers and obtained the optimal technology pathway as well as penetration rates of different powertrains and technologies. Every single automaker should meet the regulation. Therefore, the final results of the whole market could be obtained by adding up the results of all automakers. Figures 10-12 show the overall technology pathway and cost of the industry to meet the CAFC regulations from 2025-2035.

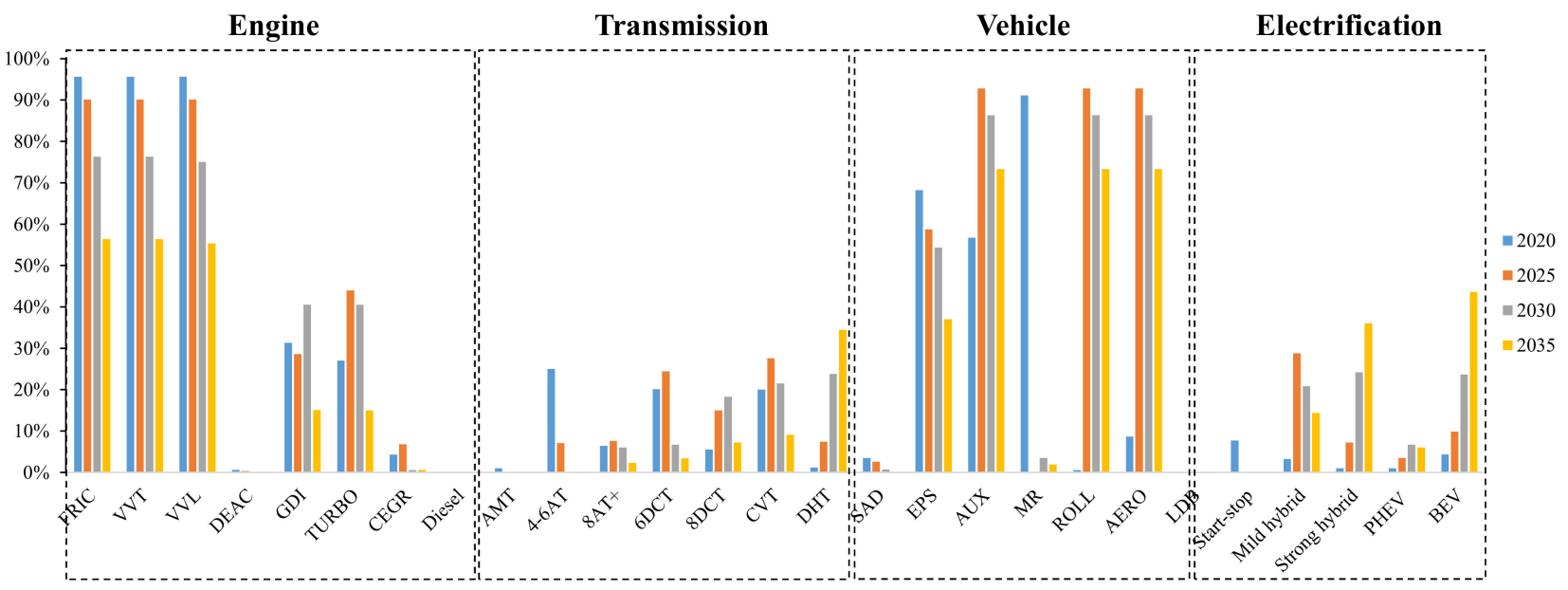

Figure 10. Technology pathways to comply with the CAFC regulation.

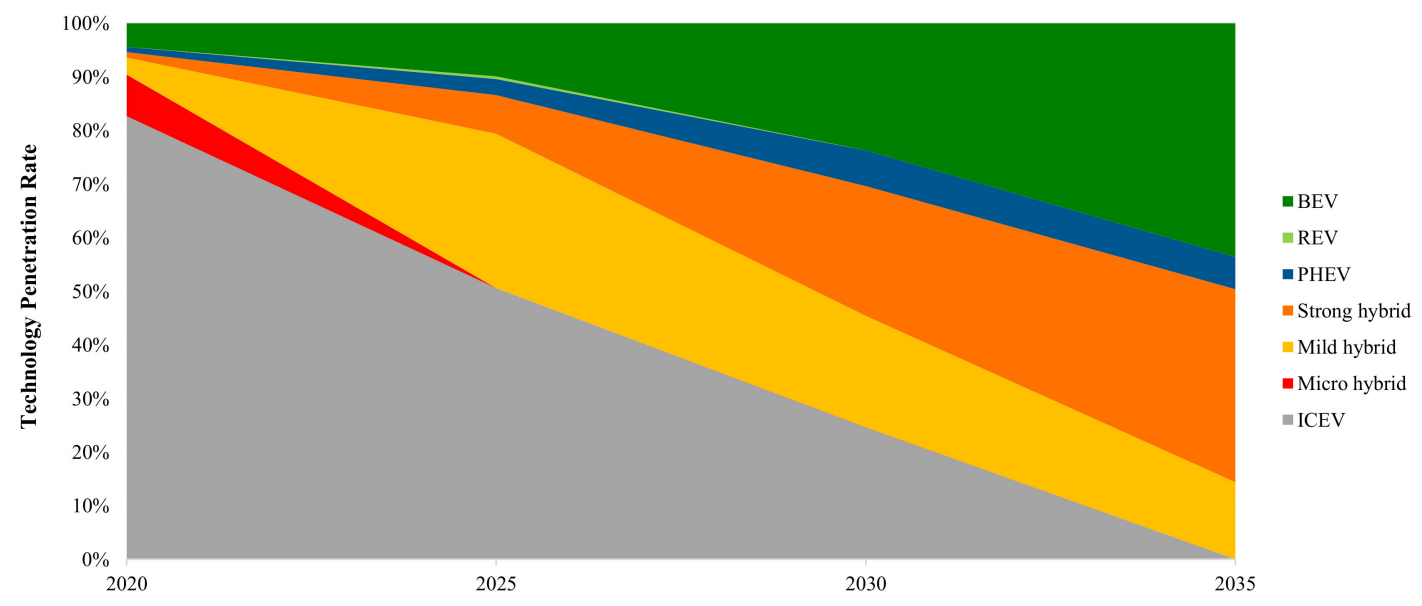

Figure 11. Penetration rates of different powertrains under the CAFC regulation. 

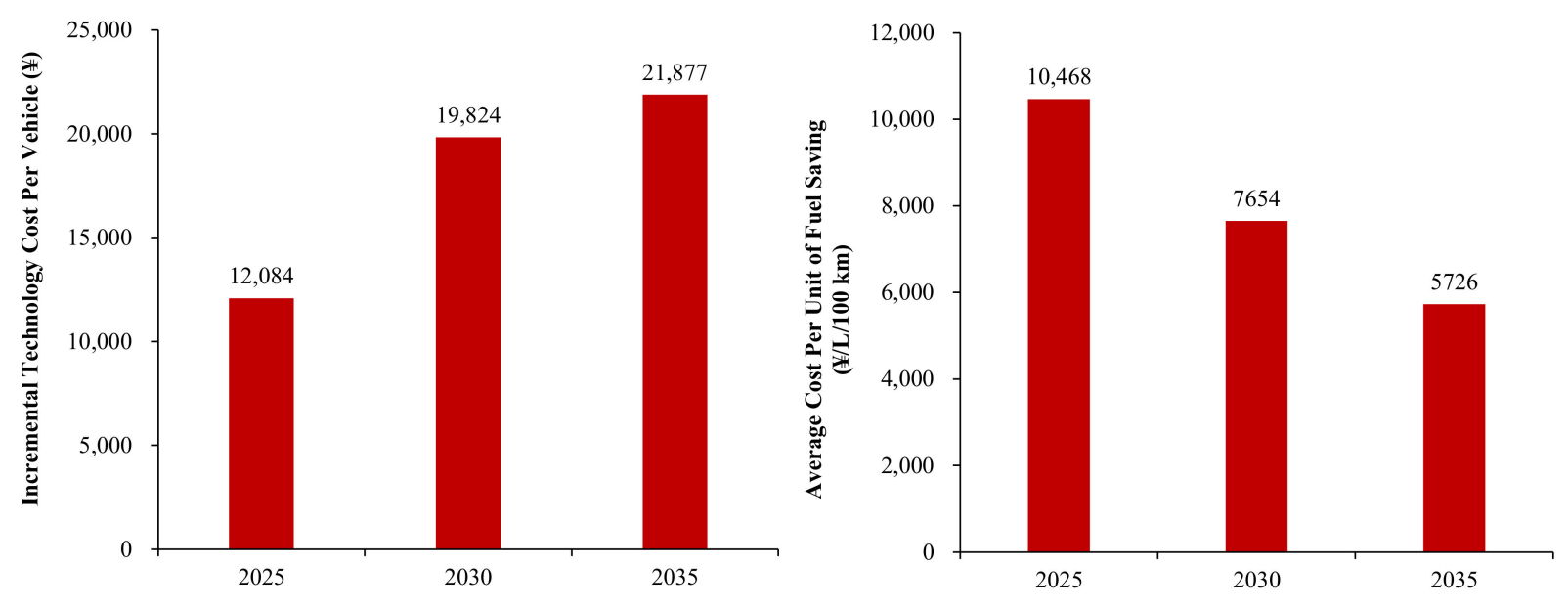

Figure 12. Average compliance cost of industry under the CAFC regulation.

It can be seen that under the CAFC regulation, the penetration rate of NEVs should be $13.4 \%$ in 2025 , of which about $10 \%$ are BEV. With the tightening of regulations, the penetration rate of BEVs and PHEVs will be $23.7 \%$ and $6.7 \%$, respectively, and mild hybrid electric vehicles (MHEVs) will be gradually replaced by strong hybrid electric vehicles in 2030. For 2035, the penetration rate of BEVs and PHEVs will be $43.6 \%$ and $6 \%$ further. For vehicles with traditional internal combustion engines, technologies of engine friction reduction, variable valve timing (VVT), and variable valve lift (VVL) are gradually becoming necessary technologies, and the application rate of improved accessory, low rolling resistance tires, and aerodynamics improvement will be significantly increased. The penetration rate of mass reduction technology was less than expected due to the restraints of the linear regulation which is based on the curb weight.

As can be seen from Figure 11, in terms of the penetrations of different powertrains, the micro hybrid technology (including start-stop technology) will be gradually phased out in 2025, and the mild hybrid electric vehicles (MHEVs) will be rapidly introduced in 2025 due to their high technology cost-effectiveness. With the tightening of regulations, the penetration rate of BEVs and PHEVs will increase, and MHEVs will gradually be replaced by strong hybrid electric vehicles in 2030. The overall market penetration of PHEVs will increase first, and then decrease due to the cost reduction of BEVs. Compared to PHEVs and BEVs, REVs are not competitive in cost-effectiveness, but they do have the product advantages that they could not only provide the electric driving experience but also solve the range anxiety problem compared to BEVs.

As mentioned above, every automaker will make their technology strategy and adjust their product matrix to comply with the regulation at the lowest cost. The objective function of the model is the total compliance cost, which means the automaker meets the policy with the minimum incremental technology cost compared to the fleet in 2019. Further, in this study, two factors were used to represent the compliance difficulty and cost: the incremental technology cost per vehicle and the average cost per unit of fuel saving. The average cost per unit of fuel saving is the result of incremental technology cost per vehicle divided by fuel reduction. The higher the average cost per unit of fuel saving, the more difficult it to comply with the regulation.

Under the CAFC regulation, compared with the fleet in 2019, the incremental technology cost per vehicle will be $¥ 12,084$, ¥19,824, and $¥ 21,877$ in 2025,2030 , and 2035 , respectively, and the average cost per $\mathrm{L} / 100 \mathrm{~km}$ of fuel-saving will be $¥ 10,468, ¥ 7654$, and $¥ 5726$, respectively. The compliance difficulty depends mainly on the game theory of two factors: the tightening of regulations and the reduction of technology cost. On the one hand, stricter regulations lead to higher compliance costs. On the other hand, with the progress of technology and production volume, the cost of technology, especially the core components (battery, motor, and so on), for new energy vehicles will directly affect the 
compliance cost. The Phase V (2021-2025) CAFC regulation will be the most difficult one to meet in the next 10-15 years. The actual CAFC value of the fleet should be reduced from $5.87 \mathrm{~L} / 100 \mathrm{~km}$ (WLTP) to $4.72 \mathrm{~L} / 100 \mathrm{~km}$, with a tightening rate of $19.6 \%$. Meanwhile, the technology cost is still relatively high. Although the tightening rate is more than $30 \%$ in Phase VI (2026-2030), the cost caused by stricter regulations will be greatly offset by the cost reduction of NEVs, the overall incremental cost of reaching the target will be lower than that of the Phase V.

\subsection{Rationale and Compliance of the Dual Credit Regulation}

As the core automotive regulation in China now, the dual credit regulation plays an important role in ensuring the penetration of NEVs and promoting the sustainable development of China's energy-saving and new energy vehicle industry. The rationale and compliance studies on the dual credit regulation are of great significance. The credit percentage requirement for OEMs and the NEV credit of a single vehicle are the two critical factors of the dual credit regulation. According to the latest edition of the dual credit regulation, the credit percentage requirements for OEMs from 2020 to 2023 are 12\%, 14\%, $16 \%$, and $18 \%$, respectively. At the same time, the average NEV credit of a single vehicle in 2019 is 4.8 . This study conducted scenario analyses on the core mechanism of dual credit regulations, as shown in Figure 13. In the Business as Usual (BAU) scenario, the credit percentage keeps a linear increase, and the percentage will be $42 \%$ in 2035 . The NEV credit of a single vehicle remains as 3 during 2021-2035. In the Alternative-Credit (AC) scenario, the required credit percentage keeps a linear increase, and the NEV credit of a single vehicle presents step decreases from 3 to 1.5, and then 1, which means the average NEV credit for a single vehicle during 2021-2025 will be 3, and the value will be 1.5 during 2026-2030, and 1 during 2031-2035. In the Alternative-Percentage (AP) scenario, the NEV credit of a single vehicle remains as 3 during 2021-2035, and the credit percentage increases exponentially rather than in a linear fashion, and the percentage in 2035 will be $100 \%$. According to historical data, it was assumed that the fuel consumption of ICEVs reduces by $2 \%$ per year, and the penetration rates of NEVs under the three scenarios are shown in Figure 13.

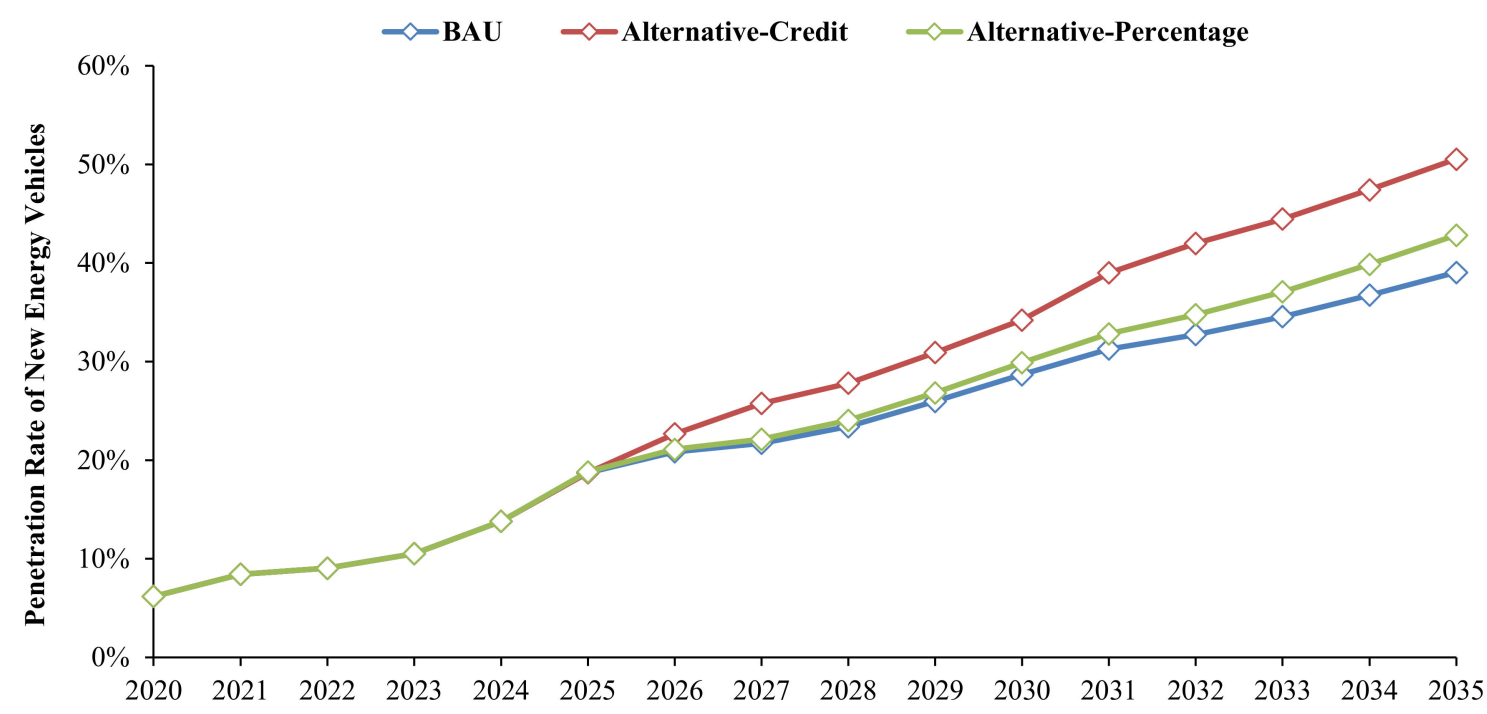

Figure 13. Penetration rate of NEVs under different dual credit scenarios.

Each curve in the figure represents the lowest limit of NEV penetration rate under the scenario. When the penetration rate is lower than this line, the regulation cannot be satisfied. It can be seen from the results that the penetration rates of new energy vehicles are more sensitive to single vehicle credit, and the influence of credit percentage requirement on the penetration rate is weaker than that of single vehicle credit. Under the BAU scenario, 
the penetration rate of new energy vehicles is the lowest, and the penetration rate of new energy vehicles is required to reach $39 \%$ in 2035 . Under the AC scenario, the penetration rate of new energy vehicles is the highest, required to reach $50.5 \%$ in 2035 . Under the AP scenario, the penetration rate requirement is $42.8 \%$. Due to the strong dilution effect of single vehicle credit, the influence of single vehicle credit on the new energy vehicle penetration rate is greater.

Figure 14 compares different regulation scenarios, namely NEV credit regulation-only, CAFC regulation-only, and dual credit regulation. In the premise condition of Figure 14, the annual average fuel consumption reduction rate for ICEVs is set as a fixed value, the final result is the penetration rate of NEVs. Based on the annual average fuel consumption reduction rate of $2 \%$ for ICEVs, it can be seen that the NEV-only regulation determines the minimum requirements of all OEMs, and the CAFC regulation is stricter than the dual credit regulation. The minimum NEV penetration rate requirement of the CAFC regulation is higher than that of the dual credit regulation. The reason is that NEVs can get double privileges on both NEV credit and CAFC credit. Meanwhile, NEV credit can one-way substitute CAFC credit, which is equivalent to the average stringency of the NEV-only regulation and the $\mathrm{CAFC}$ regulation.

In contrast, if we set the NEV penetration rate as a fixed value according to the national technology roadmap, and set the fuel consumption of ICEVs as the variable and the final result, as we can see from Figure 15, the fuel consumption of ICEVs under the CAFC regulation needs to decrease more than that of the dual credit regulations to get the penetration target of NEVs in national technology roadmap (20\% in 2025, 40\% in 2030,50\% in 2035). In 2035, the fuel consumption of ICEVs will drop to $5.3 \mathrm{~L} / 100 \mathrm{~km}$ under the dual credit regulation and will drop to $4.73 \mathrm{~L} / 100 \mathrm{~km}$ under the CAFC regulation. That is, the minimum requirement of CAFC regulation is relatively stricter.

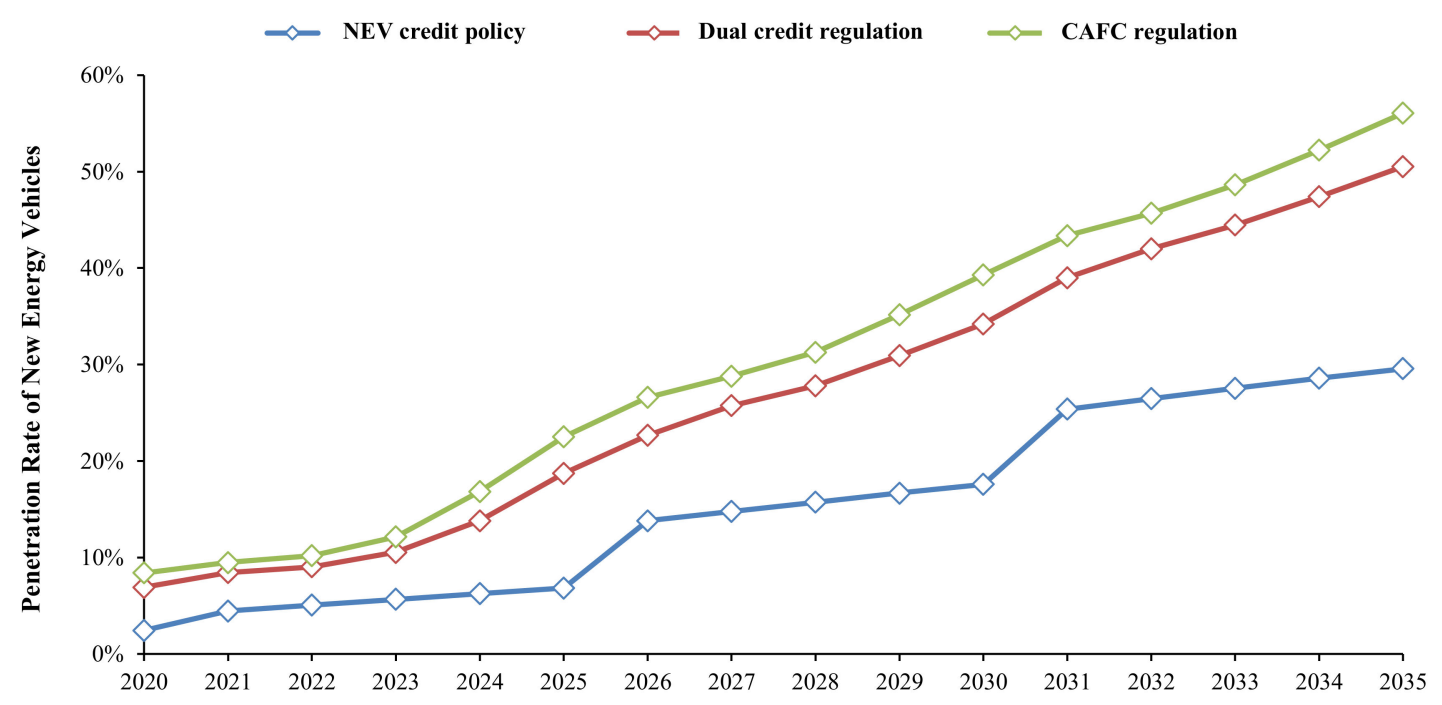

Figure 14. Comparison of the penetration of NEVs under multiple regulations. 


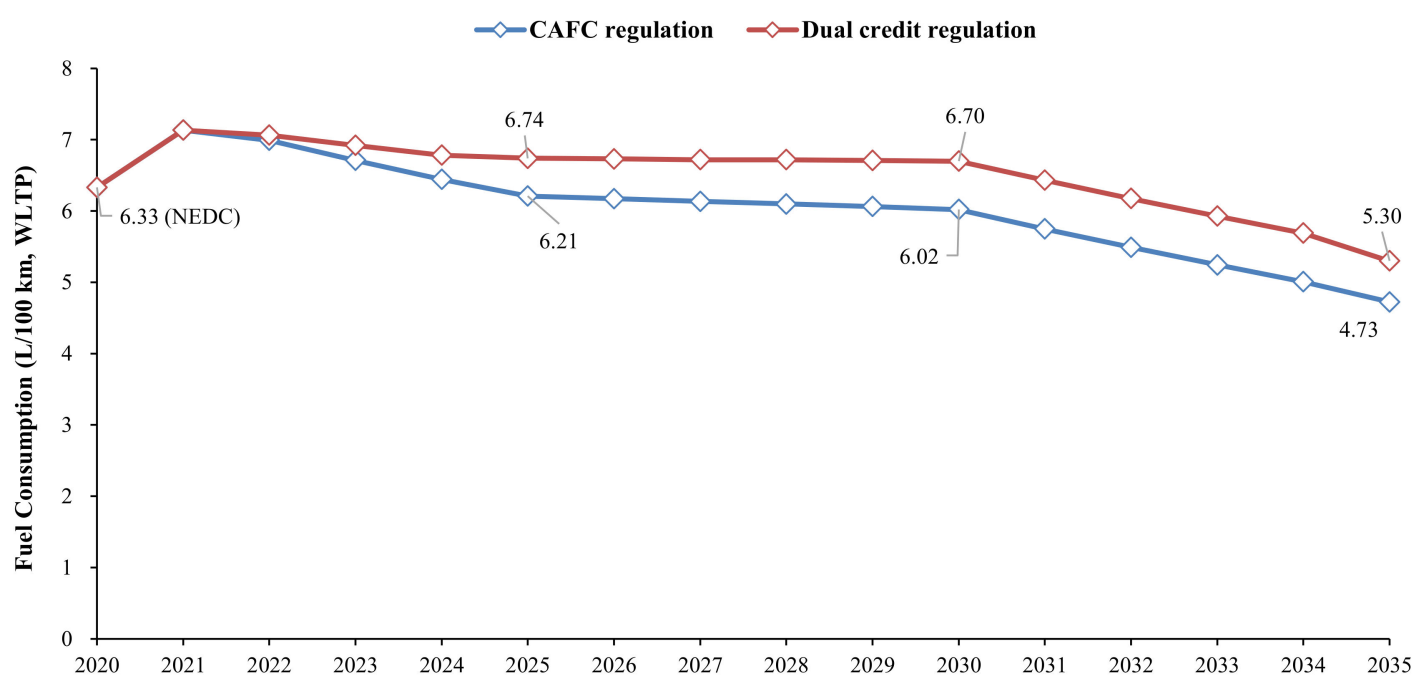

Figure 15. Comparison of fuel consumption of traditional ICEVs under multiple regulations.

Therefore, based on the comparisons of multiple regulations, the advantages of the dual credit regulation are that, on the one hand, it sets a minimum requirement for all OEMs to produce NEVs. On the other hand, it provides more flexibility for OEMs. For the backward OEMs, they can comply with the regulation by producing more NEVs or buying NEV credits. For the leading OEMs, they will be motivated to produce more NEVs to sell or substitute CAFC credits. However, in the long term, with the increasing penetration of new energy vehicles, the "averaging" effect of the dual credit regulation will inhibit the development of energy-saving and new energy vehicles. When the cost of new energy vehicles is lower than that of traditional vehicles, eliminating the connection between NEV credit and CAFC credit or only remaining the CAFC and fuel consumption limit regulations will be better for the long-term development of the energy-saving and new energy vehicle industry.

\section{Conclusions and Policy Implications}

Given the lack of the systematic evaluation model for China's fuel consumption and NEV credit regulations, this study established a hierarchical optimization decision-making model based on technology frontier curves, and a comprehensive database containing a huge number of data related to technology, product, and enterprises for the Chinese market to simulate and evaluate the technology compliance and policy impact under multiple regulations. A technology selection and policy compliance method for 2021-2035 under the multiple policies was proposed, and a systematic evaluation was conducted on the technology pathway, compliance cost, and policy design.

The results show that, for midsize vehicles, gasoline technologies still have a great cost-effectiveness advantage when the fuel-saving requirement is less than $46 \%$, and the space for PHEVs and REVs is gradually shrinking due to the cost reduction of BEVs. BEV400 will be better than PHEV70 and REV100 when the fuel-saving requirement is higher than $79 \%$. In addition, diesel engines never have the advantage of cost-effectiveness in the passenger car market.

Under the single CAFC regulation, micro hybrid technology will be gradually phased out and MHEVs will be rapidly introduced due to its high cost-effectiveness in 2025. With the tightening of regulations, the penetration rate of BEVs and PHEVs will be $23.7 \%$ and $6.7 \%$, respectively, and MHEVs will be gradually replaced by strong hybrid electric vehicles in 2030. For 2035, the penetration rate of BEVs and PHEVs will be $43.6 \%$ and $6 \%$ further. For the dual credit regulation, the single vehicle credit has a greater impact on the penetration of NEVs than corporate credit percentage limitation, and is the key factor that should be focused on. The NEV credit limitation in the dual credit regulation could push 'poor 
performance' automakers to produce the required number of NEVs and meet the bottom line. However, in the long term, when compared to the CAFC regulation, the dual credit regulation is more lenient, due to NEVs being able to access double benefits on NEV credits and CAFC credits, and NEV credit can also unidirectionally compensate CAFC credit under the dual credit policy context. With the increased penetration and cost reduction of NEVs, the 'averaging' effect of dual credit will inhibit the development of energy-saving and new energy vehicles. Therefore, eliminating the connection between NEV credit and CAFC credit or only retaining the CAFC and fuel consumption limit regulations in the future will be better for the long-term development of the energy-saving and new energy vehicle industry.

The novelty of this study mainly lies in three aspects. First, the hierarchical optimization decision-making method based on the technology frontier curve was proposed to guide the formulation of the industry technology roadmap and the decision-making strategy of OEMs. Second, a comprehensive evaluation model was established to assess China's fuel consumption and NEV credit regulation system, proposing quantitative evaluations on regulation synergy and policy compliance. Third, a technology selection model of the whole fleet in the Chinese market was established. Through refining the portrait of each OEM, the model can comprehensively evaluate the effects of regulations from the perspective of technology, product, enterprise, and the whole market.

Based on this study, some further research can be conducted. First, the technology effectiveness in this paper is based on the WLTP, and in the future, the test procedure of China's fuel consumption regulations will further switch to the China automotive test cycle (CATC) [71]. However, the data of various technologies under the CATC are scarce at present. Therefore, the accuracy of the results could be further improved in the future. On the other hand, this study mainly focuses on the total manufacturing cost of technologies and vehicles. Further studies could be conducted on the total cost of ownership (TCO) and the cost-effectiveness of different vehicles from the perspective of consumers.

Author Contributions: K.C., F.Z., and Z.L. designed the whole study; K.C. and X.L. conducted data collection; K.C. conducted modeling, results analysis, and wrote the paper; H.H. and Z.L. revised and edited the paper. All authors have read and agreed to the published version of the manuscript.

Funding: This research was funded by the National Natural Science Foundation of China, grant number U1764265, 71774100, 71690241.

Institutional Review Board Statement: Not applicable.

Informed Consent Statement: Not applicable.

Data Availability Statement: Publicly available datasets were analyzed in this study. This data can be found here: https:/ /yhgscx.miit.gov.cn/fuel-consumption-web/mainPage (accessed on 7 May 2021).

Acknowledgments: The authors would like to thank the anonymous reviewers for their reviews and comments.

Conflicts of Interest: The authors declare no conflict of interest.

\section{Abbreviations}

AMT Automated Manual Transmission

AERO Aerodynamics improvement

AUX Auxiliary systems efficiency improvement

BEV Battery Electric Vehicle

CAFC Corporate Average Fuel Consumption

CAFE Corporate Average Fuel Economy

CATARC China Automotive Technology \& Research Center

CATC China Automotive Test Cycle

CD Charge Depleting 


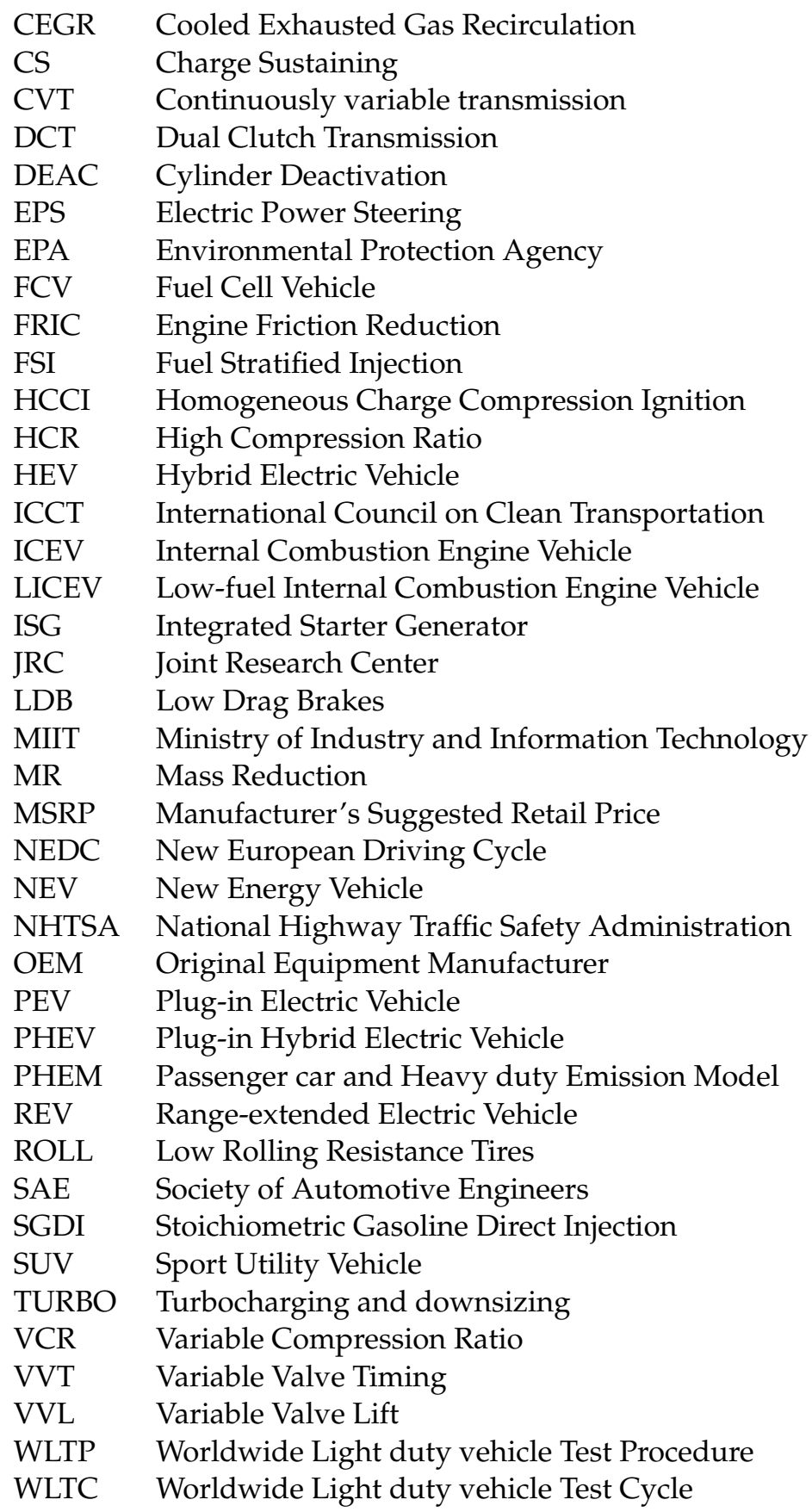

\section{References}

1. CAAM. Economic Performance of the Automobile Industry in 2020. Available online: http://www.caam.org.cn/chn/1/cate_2/ con_5232916.html (accessed on 7 May 2021).

2. National Bureau of Statistics. Statistical Communique of the People's Republic of China on National Economic and Social Development 2020. Available online: http:/ /www.stats.gov.cn/tisj/_zxfb/202102/t20210227_1814154.html (accessed on 7 May 2021).

3. Hao, H.; Wang, H.; Yi, R. Hybrid modeling of China's vehicle ownership and projection through 2050. Energy 2011, 36, 1351-1361. [CrossRef]

4. ETRI. Oil and Gas Industry Development Report at Home and Abroad in 2019; Petroleum Industry Press: Beijing, China, 2020.

5. ETRI. Oil and Gas Industry Development Report at Home and Abroad in 2020; Petroleum Industry Press: Beijing, China, 2021.

6. IEA. World Energy Outlook Special Report 2015: Energy and Climate Change. Available online: https:/ /webstore.iea.org/weo2015-special-report-energy-and-climate-change (accessed on 25 January 2021).

7. National Development and Reform Commission. Research on the Energy Saving Targets of the Transportation Sector in the 13th Five-Year Plan and 2030. Available online: http:/ / www.efchina.org/Attachments/Report/report-20170301-1-zh/report-201703 01-1-zh (accessed on 7 May 2021). 
8. Hao, H.; Wang, H.; Ouyang, M. Fuel conservation and GHG (Greenhouse gas) emissions mitigation scenarios for China's passenger vehicle fleet. Energy 2011, 36, 6520-6528. [CrossRef]

9. MEE. President Xi's Speech at the General Debate of the 75th Session of the United Nations General Assembly. 2020. Available online: https://www.mee.gov.cn/ywdt/szyw/202009/t20200923_799945.shtml (accessed on 7 May 2021).

10. SAE-China. Technology Roadmap for Energy Saving and New Energy Vehicles 2.0; China Machine Press: Beijing, China, 2020.

11. Standardization Administration of China. GB 19578-2004. Fuel Consumption Limits for Passenger Cars; Standardization Administration of China: Beijing, China, 2004.

12. Standardization Administration of China. GB 19578-2014. Fuel Consumption Limits for Passenger Cars; Standardization Administration of China: Beijing, China, 2014.

13. Standardization Administration of China. GB 19578-2019. Fuel Consumption Limits for Passenger Cars; Standardization Administration of China: Beijing, China, 2019.

14. Standardization Administration of China. GB 27999-2011. Fuel Consumption Evaluation Methods and Targets for Passenger Cars; Standardization Administration of China: Beijing, China, 2011.

15. Standardization Administration of China. GB 27999-2014. Fuel Consumption Evaluation Methods and Targets for Passenger Cars; Standardization Administration of China: Beijing, China, 2014.

16. Standardization Administration of China. GB 27999-2019. Fuel Consumption Evaluation Methods and Targets for Passenger Cars; Standardization Administration of China: Beijing, China, 2019.

17. Standardization Administration of China. GB 19578-2021. Fuel Consumption Limits for Passenger Cars; Standardization Administration of China: Beijing, China, 2021.

18. MIIT. The Parallel Scheme of Corporate Average Fuel Consumption of the Passenger Car and New Energy Vehicle Credits. 2017. Available online: http:/ / www.miit.gov.cn/n1146290/n4388791/c5826378/content.html (accessed on 7 May 2021).

19. MIIT. Decision on Revising the Parallel Scheme of Corporate Average Fuel Consumption of the Passenger Car and New Energy Vehicle Credits. 2020. Available online: http://www.miit.gov.cn/n1146285/n1146352/n3054355/n3057585/n3057592/c7982289 / content.html (accessed on 7 May 2021).

20. United States Environmental Protection Agency. Proposed Determination on the Appropriateness of the MY 2022-2025 Light-Duty Vehicle Greenhouse Gas Emissions Standards under the Midterm Evaluation; EPA: Washington, DC, USA, 2016.

21. United States Environmental Protection Agency. Draft Technical Assessment Report: Midterm Evaluation of Light-Duty Vehicle Green Gas Emission Standards and Corporate Average Fuel Economy Standards for MY 2021-2025; EPA: Washington, DC, USA, 2016.

22. Krause, J.; Donati, A.; Thiel, C. Light Duty Vehicle $\mathrm{CO}_{2}$ Emission Reduction Cost Curves and Cost Assessment-The Dione Model; Publications Office of the European Union: Luxembourg, 2017.

23. Capros, P.; Siskos, P. Primes-Tremove Transport Model V3 Model Description. Available online: https:/ / ec.europa.eu/clima/ sites/clima/files/strategies/analysis/models/docs/primes_tremove_en.pdf (accessed on 7 May 2021).

24. Mavris, D.N.; Kirby, M.R. Technology Identification, Evaluation and Selection for Commercial Transport Aircraft; Aerospace Systems Design Laboratory Publications: Atlanta, GA, USA, 1999.

25. Roth, B.A.; German, B.J.; Mavris, D.N.; Macsotai, N.I. Adaptive selection of engine technology solution sets from a large combinatorial space. In Proceedings of the 37th Joint Propulsion Conference and Exhibit, Salt Lake City, UT, USA, 8-11 July 2001.

26. Roth, B.; Mavris, D. Technology portfolio assessments using a modified genetic algorithm approach. In Proceedings of the 9th AIAA/ISSMO Symposium and Exhibit on Multidisciplinary Analysis and Optimization, Atlanta, GA, USA, 4-6 September 2002.

27. Montalbo, T.; Lee, T.M.; Roth, R.; Kirchain, R.E. Selection of Lightweighting Strategies for Use Across an Automaker's Vehicle Fleet. In Sustainable Systems and Technology; IEEE: Piscataway, NJ, USA, 2009; pp. 1-6.

28. Maddulapalli, A.K.; Iyer, P.S.; Raghavan, N.S. Selecting and Optimizing a Regulation Compliant Robust Vehicle Portfolio Mix: An Approach and a Case Study. In Proceedings of the ASME 2012 International Design Engineering Technical Conferences and Computers and Information in Engineering, Chicago, IL, USA, 12-15 August 2012; pp. 955-964.

29. Fellini, R.; Kokkolaras, M.; Papalambros, P.Y. Quantitative platform selection in optimal design of product families, with application to automotive engine design. J. Eng. Des. 2006, 17, 429-446. [CrossRef]

30. Liu, C.; Greene, D.L.; Bunch, D.S. Vehicle Manufacturer Technology Adoption and Pricing Strategies under Fuel Economy /Emissions Standards and Feebates. Energy J. 2014, 35, 3. [CrossRef]

31. Taghavi, A.; Chinnam, R.B. Assortment planning of automotive products with considerations for economic and environmental impacts of technology selection. J. Clean. Prod. 2014, 70, 132-144. [CrossRef]

32. Wang, S.; Chen, K.; Zhao, F.; Hao, H. Technology pathways for complying with Corporate Average Fuel Consumption regulations up to 2030: A case study of China. Appl. Energy 2019, 241, 257-277. [CrossRef]

33. Wang, S.; Zhao, F.; Liu, Z.; Hao, H. Heuristic method for automakers' technological strategy making towards fuel economy regulations based on genetic algorithm: A China's case under corporate average fuel consumption regulation. Appl. Energy 2017, 204, 544-559. [CrossRef]

34. Cheah, L.; Heywood, J. Meeting US passenger vehicle fuel economy standards in 2016 and beyond. Energy Policy 2011, 39, 454-466. [CrossRef]

35. Stojkovski, S.P. The Optimization of the Light-Duty Automotive Fleet for Cost Effective Fuel Efficiency. SAE Int. J. Fuels Lubr. 2009, 2, 158-166. [CrossRef] 
36. Kieckhäfer, K.; Walther, G.; Axmann, J. Integrating agent-based simulation and system dynamics to support product strategy decisions in the automotive industry. In Proceedings of the Winter Simulation Conference, Austin, TX, USA, 13-16 December 2009; pp. 1433-1443.

37. Michalek, J.J.; Papalambros, P.Y.; Skerlos, S.J. A study of fuel efficiency and emission policy impact on optimal vehicle design decisions. J. Mech. Des. 2004, 126, 1062-1070. [CrossRef]

38. Shiau, C.S.; Michalek, J. A game-theoretic approach to finding market equilibria for automotive design under environmental regulation. In Proceedings of the ASME 2007 International Design Engineering Technical Conferences and Computers and Information in Engineering Conference, Las Vegas, NV, USA, 4-7 September 2007; pp. 187-196.

39. Shiau, C.S.N.; Michalek, J.J.; Hendrickson, C.T. A structural analysis of vehicle design responses to Corporate Average Fuel Economy policy. Transp. Res. Part A Policy Pract. 2009, 43, 814-828. [CrossRef]

40. Whitefoot, K.S.; Skerlos, S.J. Design incentives to increase vehicle size created from the US footprint-based fuel economy standards. Energy Policy 2012, 41, 402-411. [CrossRef]

41. Peckham, R.; Basu, S.; Ribeiro, M. Harmonizing and Rationalizing Lightweighting within Fuel Efficiency Regulations Across NA, EU and China. SAE Int. J. Passeng. Cars Mech. Syst. 2017, 10, 455-464. [CrossRef]

42. Sallee, J.M.; Slemrod, J. Car notches: Strategic automaker responses to fuel economy policy. J. Public Econ. 2012, 96, 981-999. [CrossRef]

43. Hao, H.; Wang, S.; Liu, Z. The impact of stepped fuel economy targets on automaker's light-weighting strategy: The China case. Energy 2016, 94, 755-765. [CrossRef]

44. Plotkin, S.E. Examining fuel economy and carbon standards for light vehicles. Energy Policy 2009, 37, 3843-3853. [CrossRef]

45. Grace Haaf, C.; Michalek, J.J.; Ross Morrow, W.; Liu, Y. Sensitivity of vehicle market share predictions to discrete choice model specification. J. Mech. Design 2014, 136, 121402. [CrossRef]

46. Austin, D.; Dinan, T. Clearing the air: The costs and consequences of higher CAFE standards and increased gasoline taxes. $J$. Environ. Econ. Manag. 2005, 50, 562-582. [CrossRef]

47. Rubin, J.; Leiby, P.N.; Greene, D.L. Tradable fuel economy credits: Competition and oligopoly. J. Environ. Econ. Manag. 2009, 58, 315-328. [CrossRef]

48. Zielinski, J.; Andreucci, R.; Aktas, C.B. Prospects for Meeting the Corporate Average Fuel Economy Standards in the US. Procedia Eng. 2016, 145, 460-467. [CrossRef]

49. Fischer, C. Comparing flexibility mechanisms for fuel economy standards. Energy Policy 2008, 36, 3116-3124. [CrossRef]

50. He, H.; Bandivadekar, A. Passenger Car Fuel-Efficiency, 2020-2025 Comparing Stringency and Technology Feasibility of the Chinese and US Standards; The International Council on Clean Transportation: Washington, DC, USA, 2013.

51. He, H.; Jun, T. The New Passenger Car Fleet in China, 2010: Technology Assessment and International Comparisons; The International Council on Clean Transportation: Washington, DC, USA, 2012.

52. California Air Resource Board. Zero-Emission Vehicle Legal and Regulatory Activities and Background. Available online: https:/ / www.arb.ca.gov/msprog/zevprog/zevregs/zevregs.htm (accessed on 7 May 2021).

53. CARB. Zero Emission Vehicle Credits. Available online: https://www.arb.ca.gov/msprog/zevprog/zevcredits/2015zevcredits. htm (accessed on 7 May 2021).

54. China EV100. Tracking and Evaluation of Major New Energy vehicle market policies in the world. In Proceedings of the China EV100, Beijing, China, 23-24 January 2016.

55. Greene, D.L.; Park, S.; Liu, C. Public policy and the transition to electric drive vehicles in the US: The role of the zero emission vehicles mandates. Energy Strategy Rev. 2014, 5, 66-77. [CrossRef]

56. Wesseling, J.H.; Farla, J.C.M.; Hekkert, M.P. Exploring car manufacturers' responses to technology-forcing regulation: The case of California's ZEV mandate. Environ. Innov. Soc. Transit. 2015, 16, 87-105. [CrossRef]

57. Walther, G.; Wansart, J.; Kieckhäfer, K. Impact assessment in the automotive industry: Mandatory market introduction of alternative powertrain technologies. Syst. Dyn. Rev. 2010, 26, 239-261. [CrossRef]

58. Sykes, M.; Jonn, A. No free ride to zero-emissions: Simulating a region's need to implement its own zero-emissions vehicle (ZEV) mandate to achieve 2050 GHG targets. Energy Policy 2017, 110, 447-460. [CrossRef]

59. Liu, Z.; Liu, F.; Wang, Y.; Hao, H.; Zhao, F. Integrated Study and Combined Policy Suggestions on CAFC, NEV and Carbon Credits. Chin. J. Automot. Eng. 2017, 7, 1-9.

60. Liu, Z.; Zhao, F. Insights on the Automotive Industry; China Machine Press: Beijing, China, 2017.

61. Zou, Y.; Chen, C.; Su, H. Development and Application of the Corporate Compliance Calculation Model in CAFC and NEV Credit Management. Auto Eng. 2017, 11, 50-53.

62. Wang, Y.; Zhao, F.; Yuan, Y.; Hao, H.; Liu, Z. Analysis of Typical Automakers' Strategies for Meeting the Dual-Credit Regulations Regarding CAFC and NEVs. Automot. Innov. 2018, 1, 15-23. [CrossRef]

63. Ou, S.; Lin, Z.; Qi, L.; Li, J.; He, X.; Przesmitzki, S. The dual-credit policy: Quantifying the policy impact on plug-in electric vehicle sales and industry profits in China. Energy Policy 2018, 121, 597-610. [CrossRef]

64. Li, Y.; Zhang, Q.; Liu, B. Substitution Effect of New-Energy Vehicle Credit Program and Corporate Average Fuel Consumption Regulation for Green-car Subsidy. Energy 2018, 152, 223-236. [CrossRef]

65. Chen, K.; Zhao, F.; Hao, H.; Liu, Z. Synergistic Impacts of China's Subsidy Policy and New Energy Vehicle Credit Regulation on the Technological Development of Battery Electric Vehicles. Energies 2018, 11, 3193. [CrossRef] 
66. Zhao, F.; Chen, K.; Hao, H.; Wang, S.; Liu, Z. Technology development for electric vehicles under new energy vehicle credit regulation in China: Scenarios through 2030. Clean Technol. Environ. Policy 2019, 21, 275-289. [CrossRef]

67. He, X.; Ou, S.; Gan, Y. Greenhouse gas consequences of the China dual credit policy. Nat. Commun. 2020, 11, 5212. [CrossRef] [PubMed]

68. Chen, K.; Zhao, F.; Liu, X.; Hao, H.; Liu, Z. Impacts of the New Worldwide Light-Duty Test Procedure on Technology Effectiveness and China's Passenger Vehicle Fuel Consumption Regulations. Int. J. Environ. Res. Public Health 2021, 18, 3199. [CrossRef] [PubMed]

69. CATARC. Research on the Development Trend of China's Traditional and New Energy Vehicles through 2050; Automotive Data Center, China Automotive Technology \& Research Center: Tianjin, China, 2019.

70. SAE-China. Technology Roadmap for Energy Saving and New Energy Vehicles 1.0; China Machine Press: Beijing, China, 2016.

71. National Technical Committee of Auto Standardization. GB/T 38146.1-2019. Driving Cycle of the Chinese Vehicle Part 1: Light-Duty Vehicles; National Technical Committee of Auto Standardization: Beijing, China, 2019. 